Review

\title{
Role of bioactive lipid mediators in obese adipose tissue inflammation and endocrine dysfunction
}

\author{
Aritz Lopategi a, *, Cristina López-Vicario a , José Alcaraz-Quiles ${ }^{a}$, Verónica García-Alonso a , \\ Bibiana Rius ${ }^{\mathrm{a}}$, Esther Titos ${ }^{\mathrm{a}, \mathrm{b}}$, Joan Clària ${ }^{\mathrm{a}, \mathrm{b}, \mathrm{c}, * *}$ \\ a Department of Biochemistry and Molecular Genetics, Hospital Clínic, IDIBAPS, Barcelona 08036, Spain \\ b CIBERehd, University of Barcelona, Barcelona 08036, Spain \\ ${ }^{c}$ Department of Physiological Sciences I, University of Barcelona, Barcelona 08036, Spain
}

\section{A R T I C L E I N F O}

\section{Article history:}

Received 26 June 2015

Received in revised form

18 September 2015

Accepted 28 September 2015

Available online $\mathrm{xxx}$

\section{Keywords:}

Adipose tissue

Lipid mediators

Omega-6 and omega-3 fatty acids

\begin{abstract}
A B S T R A C T
White adipose tissue is recognized as an active endocrine organ implicated in the maintenance of metabolic homeostasis. However, adipose tissue function, which has a crucial role in the development of obesity-related comorbidities including insulin resistance and non-alcoholic fatty liver disease, is dysregulated in obese individuals. This review explores the physiological functions and molecular actions of bioactive lipids biosynthesized in adipose tissue including sphingolipids and phospholipids, and in particular fatty acids derived from phospholipids of the cell membrane. Special emphasis is given to polyunsaturated fatty acids of the omega- 6 and omega- 3 families and their conversion to bioactive lipid mediators through the cyclooxygenase and lipoxygenase pathways. The participation of omega-3derived lipid autacoids in the resolution of adipose tissue inflammation and in the prevention of obesity-associated hepatic complications is also thoroughly discussed.
\end{abstract}

() 2015 Elsevier Ireland Ltd. All rights reserved.

\section{Contents}

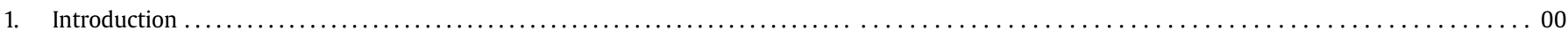

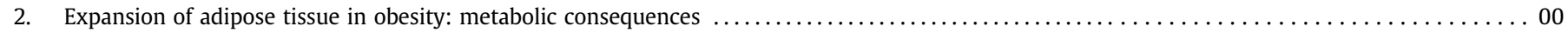

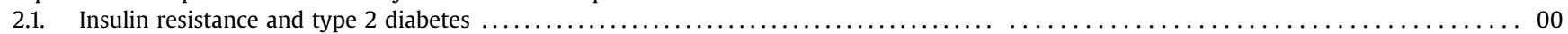

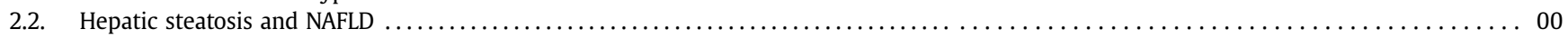

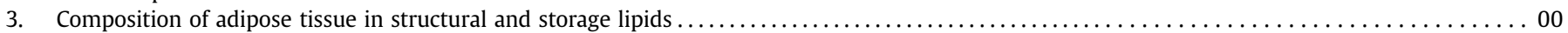

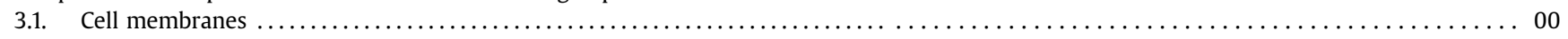

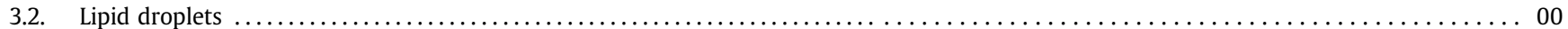

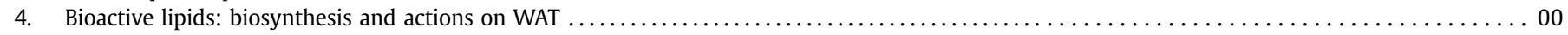

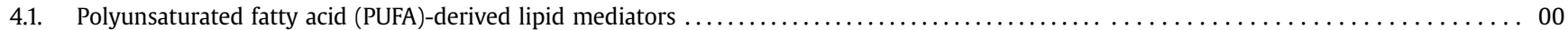

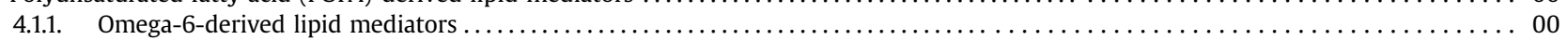

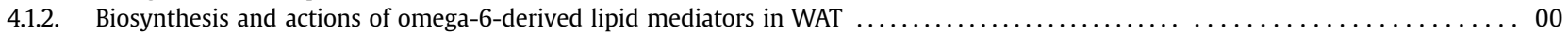

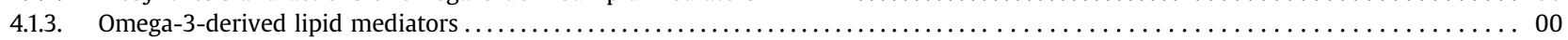

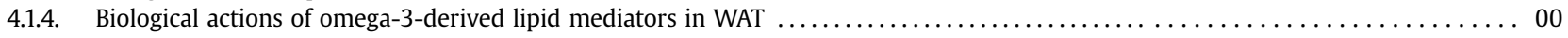

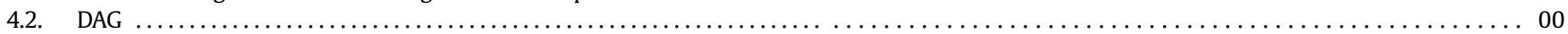

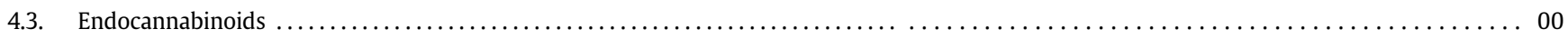

Abbreviations: BAT, brown adipose tissue; COX, cyclooxygenase; CYP, cytochrome P450; DHA, docosahexaenoic acid; EDPs, epoxydocosapentaenoic acids; EEQs, epox-

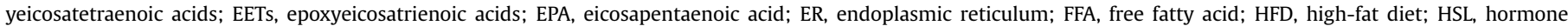

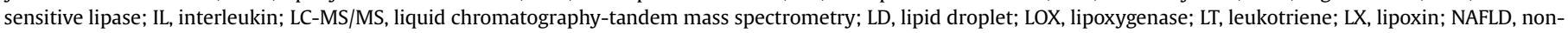

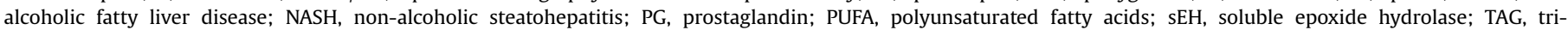
acylglycerides; TNF $\alpha$, tumor necrosis factor $\alpha$; WAT, white adipose tissue.

* Corresponding author. Department of Biochemistry and Molecular Genetics, Hospital Clínic, Villarroel 170, Barcelona 08036, Spain.

** Corresponding author. Department of Biochemistry and Molecular Genetics, Hospital Clínic, Villarroel 170, Barcelona 08036, Spain.

E-mail addresses: lopategi@clinic.ub.es, aritzlopategi@gmail.com (A. Lopategi), jclaria@clinic.ub.es (J. Clària). 


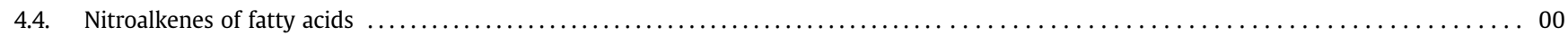

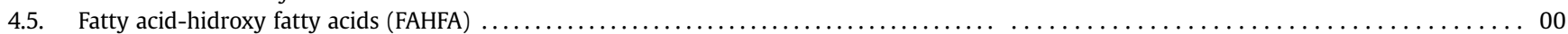

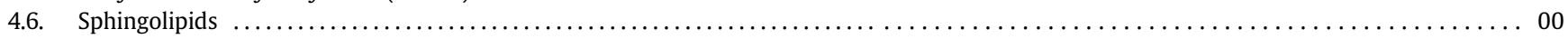

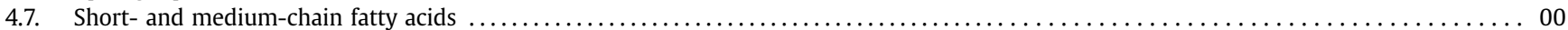

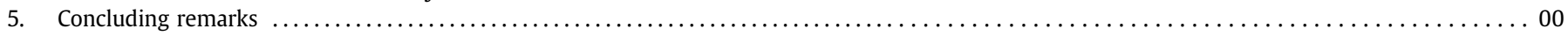

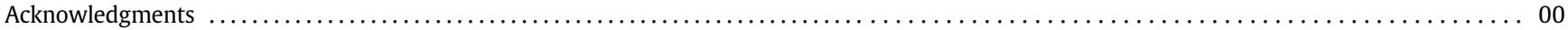

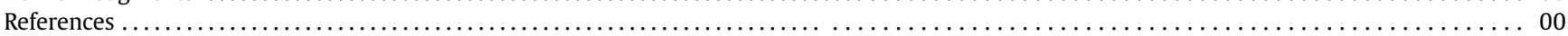

\section{Introduction}

White adipose tissue is now well recognized as a highly active metabolic tissue and an important endocrine organ that plays a major role in balancing the homeostasis of our body. Unfortunately, this balance is lost in obese individuals in whom the excessive expansion of adipose tissue gives rise to a chronic state of "lowgrade" inflammation. This unresolved inflammation of adipose tissue in obesity is deleterious and leads to many pathological sequelae including insulin resistance and type 2 diabetes, hypertension, dyslipidemia and non-alcoholic fatty liver disease (NAFLD).

Bioactive lipids play a major role in the inflammatory process. Among the different lipid mediators, polyunsaturated fatty acids and especially the essential omega- 6 arachidonic acid are the prime precursors for the biosynthesis of inflammatory mediators, generically known as eicosanoids (from the Greek eicos $a$ = twenty; for 20-carbon fatty acid derivatives). Arachidonic acid is primarily found esterified in the 2-acyl position of phospholipids in all mammalian cell membranes. The intracellular levels of unesterified arachidonic acid are remarkably low and in its free form this fatty acid is readily available as a substrate for the intracellular biosynthesis of eicosanoids. With the exception of lipoxins, the majority of eicosanoids have pro-inflammatory properties. In contrast, another family of essential polyunsaturated fatty acids, the omega- 3 family, is linked to the biosynthesis of lipid mediators with anti-inflammatory properties. Among the different lipid mediators generated from the omega-3 fatty acids docosahexaenoic acid (DHA) and eicosapentaenoic acid (EPA), resolvins, protectins and maresins have attracted much attention in recent years because they act as 'braking signals' of the persistent vicious cycle leading to unremitting inflammation. An important aspect of these endogenous omega-3-derived lipid autacoids is their critical role in the dynamic resolution of tissue inflammation.

The aim of this review is to highlight the role of bioactive lipids as key protagonists of the intracellular and intercellular communication networks in white adipose tissue (WAT). Special emphasis is placed on the novel opportunities offered by omega-3-derived lipid mediators to prevent the "low-grade" state of mild inflammation present in adipose tissue of obese individuals. This review also covers different aspects of adipose tissue physiology and pathophysiology, including the metabolic consequences of adipose tissue expansion in obese subjects, the structural and storage lipid composition of adipose tissue and a detailed enumeration of the principal and most common bioactive lipids present in adipose tissue and their biosynthesis and actions on adipocytes and other insulin-sensitive cells.

\section{Expansion of adipose tissue in obesity: metabolic consequences}

WAT is an anatomical term for loose connective tissue composed of adipocytes or fat cells. Adipocytes are nucleated cells comprising a characteristic unilocular lipid droplet mainly composed of triglycerides (TAG) and cholesterol esters, which occupy most of the cell, and a thin rim of cytoplasm displaced to the periphery (Redinger, 2009). The physical adaptability and the storage capacity of adipocytes are key components of their function. Indeed, during times in which energy intake is higher than the metabolic demand, adipocytes can expand nearly 1000-fold in volume and 10-fold in diameter in order to store the excess of fuel as TAG (Redinger, 2009). In contrast, in periods of food restriction or in periods demanding more energy expenditure, adipose tissue serves, via lipolysis, as the major source of energy. Under starving conditions, lipolysis is an essential mechanism whereby ratelimiting enzymes such as hormone-sensitive lipase (HSL) and monoacylglycerol lipase (MAGL) catalyze the hydrolysis of TAG to release free fatty acids (FFA) into the circulation (Carmen and Victor, 2006). Circulating FFA are subsequently taken up via the fatty acid binding protein (FABP) and fatty acid translocase (FAT/ CD36) by metabolically active and insulin-sensitive tissues (primarily skeletal muscle and liver). These tissues use FFA as substrates for the generation of the high-energy nucleotide adenosine triphosphate (ATP) (Redinger, 2009).

The expansion of WAT occurring in obese individuals leads to prevailing high levels of hypoxia and chronic inflammation in this tissue. This inflammation is described as "metainflammation" and is characterized by a "low-grade", "long-term" inflammatory res ponse triggered by nutrients and metabolic surplus (Hotamis ligil, 2006). It involves the rise in pro-inflammatory cytokines (i.e. tumor necrosis factor- $\alpha$ (TNF- $\alpha$ ), interleukin (IL)-6, IL-1 $\beta$, monocyte chemoattractant protein-1 (MCP-1)) and adipokines (i.e. leptin and resistin) (Ouchi et al., 2011). In parallel, a reduction in antiinflammatory and insulin-sensitizing adipokine adiponectin signals the onset of metabolic dysfunction in obese individuals (Ouchi et al., 2011). Among the metabolic consequences of this persistent state of inflammation insulin resistance leading to type-2 diabetes and hepatic steatosis leading to NAFLD are the most clinically relevant (Hotamisligil, 2006; Ouchi et al., 2011).

\subsection{Insulin resistance and type 2 diabetes}

Insulin resistance is one of the most important sequelae of obesity. Insulin resistance is defined as a reduced response of target tissues, such as the skeletal muscle, liver, and adipose tissue, to insulin, compared with subjects with normal glucose tolerance without a family history of diabetes (DeFronzo and Tripathy, 2009). Although skeletal muscle is the predominant site of insulinmediated glucose uptake in the postprandial state, adipose tissue plays a major role in the development of peripheral insulin resistance. In fact, in obese subjects, the degree of insulin resistance is directly correlated with the serum levels of pro-inflammatory adipokines (i.e. TNF $\alpha$, IL-6, and MCP-1) (Ouchi et al., 2011; de Luca and Olefsky, 2008). In parallel to the heightened secretion of inflammatory adipokines, there is an activation of the c-jun- $\mathrm{N}$ terminal kinase (JNK) and inhibitor of $\kappa$ kinase (IKK) pathways and their downstream signaling cascades by stress sensors through classical receptor-mediated mechanisms (Shoelson et al., 2006). 
JNK and IKK activation in turn induces insulin resistance by disrupting tyrosine phosphorylation of insulin receptor substrate-1 (IRS-1), a protein that connects the insulin receptor to the phosphoinositide 3-kinase (PI3K) signaling cascade (DeFronzo and Tripathy, 2009). In addition, the increased release of FFA by obese adipose tissue is a major determinant of impaired insulinstimulated glucose uptake into muscle (Ebbert and Jensen, 2013).

\subsection{Hepatic steatosis and NAFLD}

Dysregulated adipose tissue function also has negative consequences in the liver. In fact, adipose tissue and the liver have immediate access to a vast network of blood vessels that implicate direct connection between these two organs. This connection is exemplified by the observation that NAFLD is one of the major metabolic consequences of obesity (Angulo, 2002; Sanyal, 2005). NAFLD is a condition ranging from simple accumulation of TAG in the cytoplasm of hepatocytes (steatosis or fatty liver) to steatosis combined with inflammation (steatohepatitis or NASH) (Angulo, 2002; Sanyal, 2005). Although generally asymptomatic, hepatic steatosis is no longer regarded as a neutral bystander, but rather as a pre-morbid condition that increases the vulnerability of this organ to progress to steatohepatitis and to more severe forms of liver damage (Angulo, 2002; Sanyal, 2005). Indeed, steatotic livers are more susceptible to the tissue-damaging effects of oxidative stress and inflammatory mediators, and transition to steatohepatitis represents a critical step in the progression to hepatic fibrosis and cirrhosis (Angulo, 2002; Sanyal, 2005). Although the exact mechanisms linking adipose tissue dysfunction and NAFLD have not been completely delineated, the exacerbated secretion of FFA and pro-inflammatory and insulin resistant adipokines (TNF $\alpha$ and IL-6) accompanied by reduced release of adiponectin by adipose tissue has a direct impact on liver cells (Angulo, 2002; Sanyal, 2005). Moreover, altered hepatic insulin sensitivity is a driving force for impaired hepatic FFA oxidation and de novo lipogenesis, which also contribute to the development of NAFLD (Tilg and Moschen, 2008).

\section{Composition of adipose tissue in structural and storage lipids}

The lipid composition of adipose tissue is strongly dependent on the diet. Differences in adipose tissue composition reported between racial groups, infant vs. adult and gender rapidly disappear when a diet of similar fatty acid composition is consumed (Damsgaard et al., 2013; Field et al., 1985). This section describes the lipid composition of fat cells categorized as structural lipids (i.e. lipids located within the cell membranes) or storage lipids (located within the unilocular lipid droplet).

\subsection{Cell membranes}

As with any other type of cell in the body, adipocytes are bound by a plasma membrane composed of carbohydrates, proteins and especially lipids. The carbohydrates in the cell membranes appear on the outside bound to lipids (glycolipids, such as cerebrosides and gangliosides) or to proteins (glycoproteins) forming the glycocalix that provides adhesion properties to the cell and participates in lymphocyte homing (Dejana et al., 1994; Ekyalongo et al., 2015). Apart from their structural and biophysical membrane functions, membrane lipids bound to carbohydrates have no bioactive effects on the cell, and therefore are not discussed in this review. Proteins are the second most abundant component of the cell after lipids. They can be transmembrane proteins with an extracellular part that interacts with the extracellular environment and an intracellular domain interacting with signal transducers or with cytosolic proteins in the cytoplasmic layer of the membrane (Harvey Lodish et al., 2000). There are also proteins that temporally interact with the membrane, including phospholipases (PL) A1 and A2 (PLA1 and PLA2) that release fatty acids in the SN1 and SN2 positions from the phospholipids; PLC, which releases diacylglycerol (DAG) from phospholipids; and sphingomyelinase (SMase), which hydrolyzes sphingomyelin to ceramide (see Section 4) (Balsinde and Dennis, 1997).

Phospholipids are the most abundant lipid components of the cell membrane. Phospholipids are amphipathic molecules containing both hydrophilic and hydrophobic moieties. For example, phosphoglycerides or glycerophospholipids are composed of a glycerol backbone with two fatty acids esterified to the SN1 and SN2 positions, and a phosphate group bound to the third hydroxyl group. This phosphate group is esterified to another hydroxyl group on another hydrophilic compound, such as choline, ethanolamine, serine or inositol, forming different phospholipids with unique properties (Balsinde et al., 1997). The fatty acids in glycerophospholipids can be saturated or unsaturated, and within these either mono or polyunsaturated, or a combination of both. Phospholipids are the most important precursors of fatty acids released intracellularly upon the action of PLA1 and PLA2. FFAs within the cytoplasm are toxic and are rapidly converted into biologically active lipid mediators by lipoxygenases and cyclooxygenases. The different derivatives and biological actions of these lipid mediators are extensively discussed in Section 4 of this review. On the other hand, sphingolipids such as sphingomyelin are formed by ceramide and phosphocoline or phosphoethanolamine that lacks the glycerol backbone. In this case, lipids are bound to a single sugar residue or to an oligosaccharide forming cerebrosides or gangliosides, respectively (Kolter et al., 1999). SMase activity hydrolyzes sphingomyelin into ceramide, sphingosine and phosphorylcoline (See Section 4.6 for more details). Finally, sterols are also lipid components of the cell membranes. Sterols are composed of a four-ring hydrocarbon structure with different groups at the two ends of the structure (Cantafora and Blotta, 1996). The most common sterol is cholesterol, which has a hydroxyl substituent on one end of the ring and a six-carbon tail with two methyl groups at positions 1 and 5 in the other. Membrane cholesterol may exert some biological activity since this lipid can post-translationally modify hedgehog signaling (Alcedo and Noll, 1997; Beckers et al., 2007).

\subsection{Lipid droplets}

Lipid droplets (LD) (also called lipid bodies, oil bodies or adiposomes) are considered a bona fide organelle present in almost all vertebrate cells, some plant cells and several yeasts and prokaryotes (Waltermann and Steinbuchel, 2005; Murphy, 2001). LD are composed of a hydrophobic core, mainly consisting of neutral lipids such as TAG and cholesterol esters surrounded by a phospholipid monolayer (as opposed to the normal bilayer of the other organelles) (Fujimoto and Parton, 2011). The hydrophilic phosphate group of phospholipids faces the aqueous cytoplasmic space, whereas the hydrophobic acylic tails are towards the inner part of the LD in contact with lipids accumulated in its core (Thiam et al., 2013). Several proteins are associated with LD, giving structural stability to its phospholipid monolayer. These proteins are implicated with lipid metabolism and signaling (Brasaemle, 2007). Interestingly, some proteins that are normally associated with the cytoplasm have been identified to be located in the LD core; but how their structure or function remains active in such a hydrophobic environment is unclear (Robenek et al., 2005). The major role of $L D$ is the storage of lipids and cholesterol for energy purposes and for the formation and renewal of membranes (Thiam et al., 2013). LD can also participate in the inflammatory response 
and are potentially involved in the pathogenesis of metabolic disorders such as obesity and atherosclerosis (Greenberg et al., 2011; Bozza and Viola, 2010; Krahmer et al., 2013).

The most widely accepted model of LD formation establishes the cellular origin in the endoplasmic reticulum (ER), where the enzymes catalyzing the end-steps of neutral lipid biosynthesis are located (Murphy, 2001; Buhman et al., 2001; Martin and Parton, 2006; Robenek et al., 2004). In the ER, nascent neutral lipids accumulate in the leaflets of the ER membrane forming a protuberance at the outer leaflet of the membrane that closes forming the LD surrounded by a phospholipid monolayer serving as an emulsifying agent (Thiam et al., 2013). Although the exact mechanisms are not yet clear, it is likely that several proteins contribute to the stabilization and release of the nascent LD. Among them, it has been proposed that members of the perilipin family (or PAT family) including perilipin, adipophilin and TIP47 control LD lipolysis and stabilization. Perilipin 1 (Plin1) was the first member of the PAT family described and is the best characterized. Upon formation, Plin1 is recruited to LD where it has a half-life exceeding $70 \mathrm{~h}$ under basal non-lipolytic conditions (Kovsan et al., 2007). Plin1 activates fat-specific protein 27 (Fsp27, or CIDEC) which promotes droplet fusion, emptying small LD into large droplets (Gong et al., 2011). Another protein of the PAT family that is present in the nascent LD after budding is TIP47 (or perilipin 3) (Wolins et al., 2005, 2003), which is recruited to the nascent LD on the ER surface when cells are incubated with fatty acids (Skinner et al., 2009). As the droplet starts growing, it migrates from the ER to the center of the adipocyte gradually losing TIP47 content while gaining adipophilin (Wolins et al., 2005). Adipophilin (or perilipin 2) is only stable while in contact with the $\mathrm{LD}$, and it is rapidly degraded by the proteasome in the cytoplasm (Gross et al., 2006; Masuda et al., 2006; Xu et al., 2005). As the LD grows further, perilipin 1 replaces the other proteins in such a way that the mature adipocyte unilocular LD is coated almost exclusively by perilipin 1 (Wolins et al., 2005).

In the cell, LD store TAG and cholesteryl esters, which are hydrolyzed when cholesterol or fatty acid levels are depleted. Cholesterol is released for the production of steroid hormones and for renewal of the cellular membrane (Hu et al., 2010). On the other hand, fatty acids serve either as scaffolds of the membrane phospholipids, for energy production through $\beta$-oxidation or for the biosynthesis of bioactive lipid mediators. HSL is the first and best characterized enzyme involved in TAG hydrolysis (lipolysis) (Holm et al., 1988). HSL is highly expressed in adipocytes and exerts hydrolytic activity over TAG, diacylglycerol (DAG) and cholesteryl and retinol esters (Fredrikson et al., 1981; Pittman et al., 1975; Wei et al., 1997). For decades HSL was thought to be the major adipocyte lipase until some studies unexpectedly revealed that HSL null mice retain TAG lipase activity with accumulation of DAG, suggesting that other lipases are implicated in TAG lipolysis (Haemmerle et al., 2002; Osuga et al., 2000; Wang et al., 2001). This controversy was solved when adipose TAG lipase (ATGL) was later identified (Jenkins et al., 2004; Zimmermann et al., 2004). ATGL hydrolyzes TAG to DAG releasing a FFA, whereas HSL hydrolyzes DAG to monoacylglycerol (MAG) again releasing another fatty acid. Finally, another enzyme acting downstream and designated MAG lipase converts MAG into a fatty acid and glycerol (Yang et al., 2010). Plin1 and PKA appear at the center of this process regulating the activity of both HSL and ATGL either directly or indirectly. PKA-mediated phosphorylation of HSL induces the docking of HSL to the LD monolayer in close association with Plin1, thus favoring lipolysis (Sztalryd et al., 2003; Granneman et al., 2007). Under basal conditions, Plin1 is associated with CGI-58 on the LD surface, and when Plin1 is phosphorylated by PKA, CGI-58 is released and can interact with ATGL, thereby increasing its activity (Lass et al., 2006). Fsp27 also plays a double role in the regulation of ATGL activity: in the LD it inhibits lipolysis by binding to ATGL (Grahn et al., 2014), whereas in the nucleus it potentiates Erg1-negative regulation of the ATGL promoter (Singh et al., 2014).

The increased release of FFA from LD by TAG lipolysis in obese adipose tissue contributes to a great extent to the development of insulin resistance. For example, a reduction in Plin 1 expression is associated with an increased rate of lipolysis that promotes systemic insulin resistance (Greenberg et al., 2011). In this regard, adipocytes from Plin1-null mice have an increased rate of lipolysis, and despite these mice being leaner than wild-type mice, they develop insulin resistance with aging (Tansey et al., 2001; Martinez-Botas et al., 2000). In humans, three individuals carrying a missense heterozygous mutation in the Plin1 gene (PLIN1) showed partial lipodystrophy, with loss of adipose tissue, along with insulin-resistant diabetes, hypertriglyceridemia and hepatic steatosis (Gandotra et al., 2011).

In addition to Plin1, knockdown of FSP27 expression increases the rate of basal lipolysis, an effect that is reversed by overexpressing FSP27 (Puri et al., 2007; Keller et al., 2008; Liu et al., 2009; Nordstrom et al., 2005; Ranjit et al., 2011; Kim et al., 2008a). Moreover, FSP27-null mice have a similar phenotype to that of Plin1-null mice, having reduced fat mass and increased lipolysis (Nishino et al., 2008). In humans, a homozygous nonsense mutation in FSP27 has been reported in a patient with lipodystrophy, insulin-resistant diabetes, hypertriglyceridemia, and hepatic steatosis. Another two proteins (seipin and caveolin-1) related to LD biology are involved in the development of lipodystrophy. Mutations in the seipin gene reduce TAG storage capacity in adipocytes, with a nearly complete absence of adipose tissue and with insulin resistance, diabetes, hypertriglyceridemia and hepatic steatosis (Magre et al., 2001). Similar features have been reported in a patient with a homozygous nonsense mutation in the gene coding for caveolin-1, which is part of the LD proteome (Kim et al., 2008b).

It has been proposed that LD have a role in the production of inflammatory and anti-inflammatory lipid mediators (Bozza and Viola, 2010; Dichlberger et al., 2013). In this regard, the number of LD has been shown to increase during the interaction of macrophages with pathogens, such as parasites (Melo et al., 2003), bacteria (Peyron et al., 2008; Daniel et al., 2011; Cardona et al., 2000; Tanigawa et al., 2008; Cao et al., 2007) and viruses (Barba et al., 1997; Samsa et al., 2009). Moreover, during infection, LD are mobilized into phagosomes, so the pathogen can use them as energy sources and for increased production of inflammatory mediators.

\section{Bioactive lipids: biosynthesis and actions on WAT}

Bioactive lipid mediators have been increasingly recognized as important endogenous regulators of key cellular processes. Fig. 1 illustrates a schematic representation of the most commonly described lipid mediators generated by adipocytes. The majority of these bioactive mediators originate from the cleavage of lipid constituents of cellular membranes under the activity of PLs, in particular PLA1 and PLA2, which release fatty acids from phospholipids, and PLC, which generates DAG from membrane phospholipids. In the free form, fatty acids are toxic in the cytosol, and are therefore readily converted into a number of lipid mediators, including omega- 6 and omega- 3 derivatives, fatty acid hydroxyl fatty acids (FAFH), nitroalkenes and endocannabinoids (Fig. 1). On the other hand, sphingolipids found in animal cell membranes are converted by the enzyme SMase into ceramide, which is subsequently hydrolyzed by ceramidase into a sphingosine molecule plus a FFA. Both ceramide and sphingosine are phosphorylated into ceramide 1-phosphate or sphingosine 1-phosphate, respectively (Fig. 1). In addition to cell membrane-derived lipids, TAG stored in 


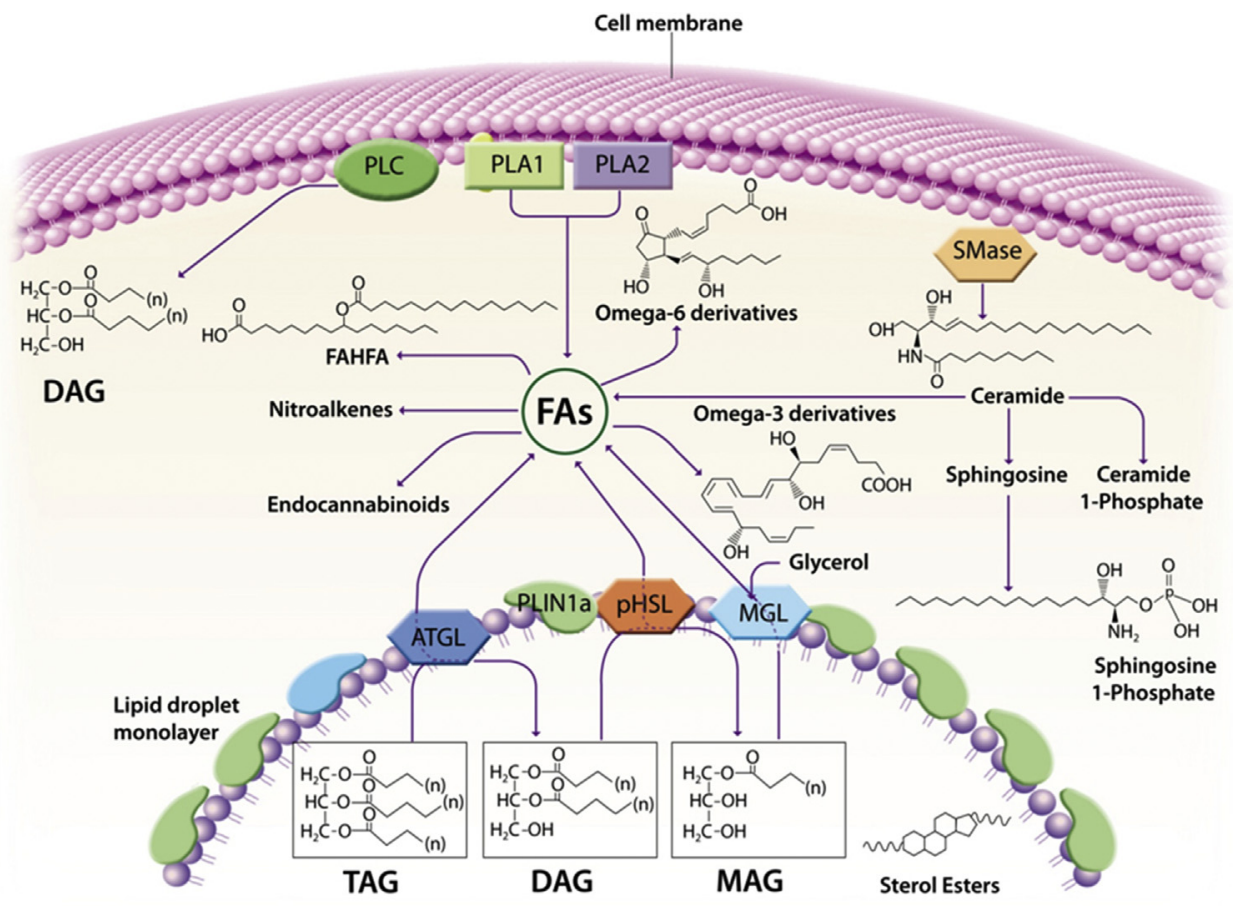

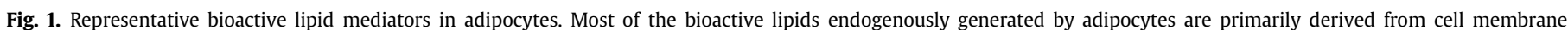

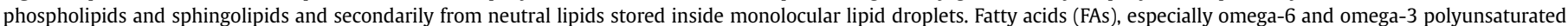

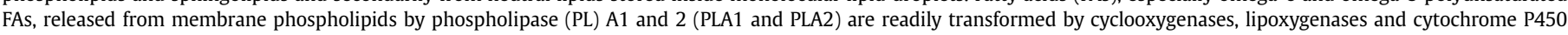

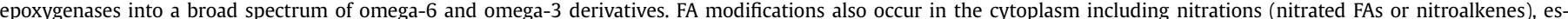

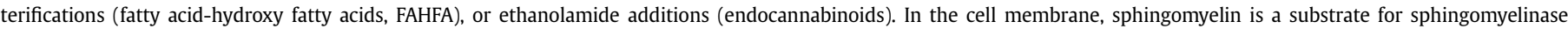

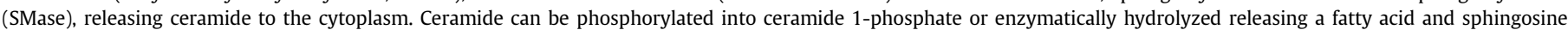

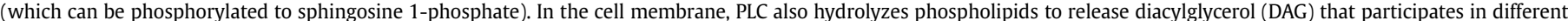

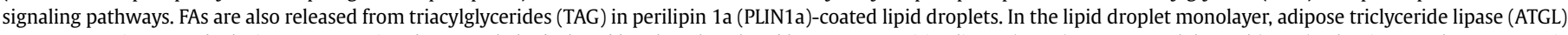

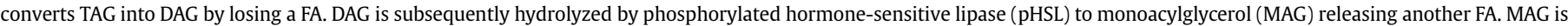
finally hydrolyzed into a third FA and glycerol by the actions of monoacylglycerol lipase (MGL).

the unilocular LD of adipocytes can release FFA into the cytosol by the concerted activities of ATGL, HSL and MGL present in the phospholipid monolayer coating the LD (Fig. 1).

\subsection{Polyunsaturated fatty acid (PUFA)-derived lipid mediators}

PUFAs cannot be synthesized de novo by mammalian cells and are therefore termed as "essential" because they must be obtained in adequate amounts from the diet (Lopez-Vicario et al., 2015a; Simopoulos, 1999). PUFAs are of utmost importance for mammalian cellular processes as they are the precursors of most cell-signaling molecules bearing a lipid structure, that is, lipid mediators. Indeed, PUFAs are unique fatty acids in the sense that they have multiple double bonds with a low dissociation energy rendering them very reactive to become easily oxidized to hydroperoxy and hydroxy derivatives (Lopez-Vicario et al., 2015a). There are two families of PUFAs depending on the carbon position of the first double bond from the methyl end (omega end): omega- 6 and omega-3. In general terms, lipid mediators derived from omega-6-PUFA exert inflammatory, atherogenic and prothrombotic effects whereas those derived from omega-3PUFA are anti-inflammatory and pro-resolving. Given that the current Western diet is very high in omega- 6 and the ratio of omega-6/omega-3 PUFAs has risen to up to 20-30:1 (Simopoulos, 1999), pro-inflammatory and pro-thrombotic eicosanoids generated from omega- 6 fatty acids are produced in larger quantities than those derived from omega- 3 fatty acids (Lopez-Vicario et al., 2015a; Schmitz and Ecker, 2008). This explains why dietary changes characterized by a lower consumption of omega-3-PUFA and modern agriculture (animals fed on diets rich in omega-6s) are believed to be the origin of the higher incidence of thrombotic, inflammatory and carbohydrate and lipid disorders in our society (Schror, 1990; Bagga et al., 2003; Calder, 2006). The biosynthetic and signaling pathways and the cellular actions of lipid mediators derived from essential omega- 6 and omega- 3 fatty acids are described in detail in the following paragraphs.

\subsubsection{Omega-6-derived lipid mediators}

Arachidonic acid, an essential omega-6 PUFA, is the precursor of the biosynthesis of eicosanoids (Astudillo et al., 2012). There are two classical routes of eicosanoid biosynthesis in mammals: the cyclooxygenase (COX) pathway that results in the formation of prostaglandins (PGs) and thromboxane (TX); and the lipoxygenase (LOX) pathway that catalyzes the formation of leukotrienes (LTs) and hydroxyeicosatetraenoic acids (HETEs) (Fig. 2) (Samuelsson et al., 1987; Romano and Claria, 2003). Apart from the COX and LOX pathways, arachidonic acid can also be converted into biological active mediators by cytochrome P-450 (CYP) epoxygenases (Fig. 2) (Spector and Norris, 2007). CYP epoxygenases are the socalled third branch of arachidonic acid metabolism and add oxygen across one of the four double bonds of this PUFA to generate three-membered ethers known as epoxyeicosatrienoic acids (EETs) (Spector and Norris, 2007). These epoxides act in an autocrine and paracrine fashion regulating vascular tone, inflammation, hyperalgesia and organ and tissue regeneration (Zeldin, 2001; Panigrahy et al., 2013). Finally, the eicosanoid family includes the lipoxins (LXs), a unique class of potent bioactive lipid mediators resulting 


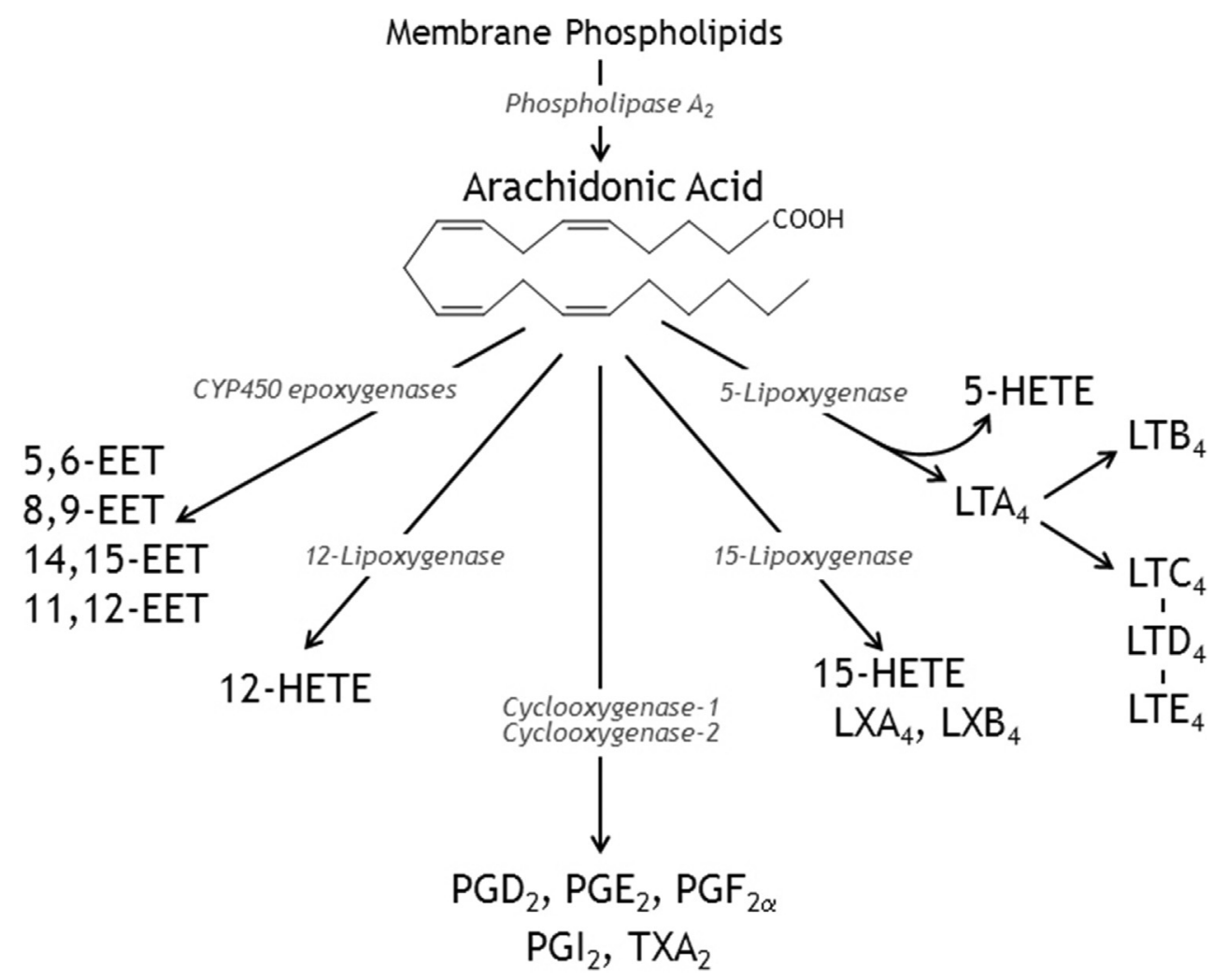

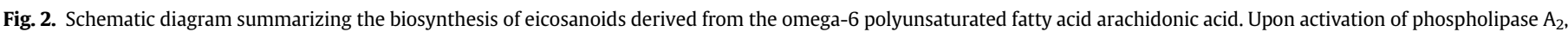

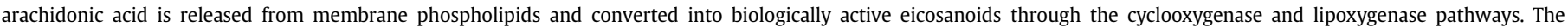

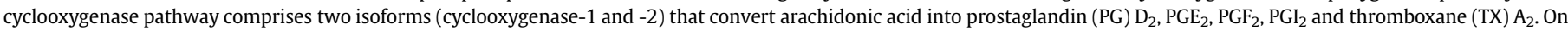

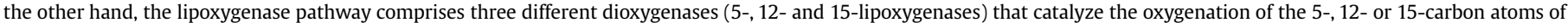

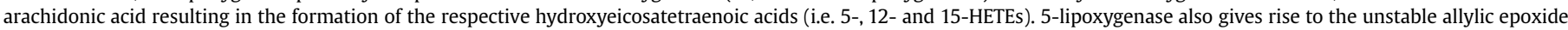

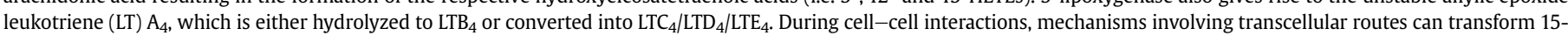

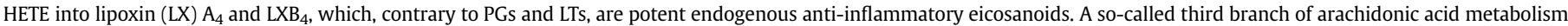
is represented by the CYP450 epoxygenases, which convert this fatty acid into epoxyeicosatrienoic acids (EETs).

from the interaction between individual LOXs and, in the presence of aspirin, between COX-LOX interactions (Fig. 2) (Samuelsson et al., 1987).

4.1.1.1. The COX pathway. COX, the key enzyme in the biosynthesis of PGs, has two different isoforms: COX-1, which is constitutively expressed, and COX-2, which is inducible (Kujubu et al., 1991; Xie et al., 1991). Both COX isoforms convert arachidonic acid into $\mathrm{PGG}_{2}$ and subsequently into $\mathrm{PGH}_{2}$, which is finally converted by specific terminal synthases into $P G s$ of the $D_{2}, E_{2}, F_{2}$ and $I_{2}$ series as well as into TXA 2 (Chandrasekharan and Simmons, 2004). Both $\mathrm{PGI}_{2}$ and TXA $\mathrm{A}_{2}$ have a very short half-life and are rapidly hydrolyzed to the inactive compounds 6-keto- $\mathrm{PGF}_{1 \alpha}$ and $\mathrm{TXB}_{2}$, respectively. $\mathrm{PGD}_{2}$ is also readily dehydrated to the cyclopentenone PGs of the $\mathrm{J}_{2}$ series $\left(\mathrm{PGJ}_{2}\right.$ and 15-deoxy- $\Delta^{12,14}-\mathrm{PGJ}_{2}\left(15 \mathrm{~d}-\mathrm{PGJ}_{2}\right)$ ) (Chandrasekharan and Simmons, 2004). COX products act as autocrine or paracrine hormones, maintaining homeostasis within their cells of origin or in neighboring cells in the tissue. These eicosanoids bind to at least ten types and subtypes of prostanoid receptors belonging to the family of the seven transmembrane $G$ protein-coupled receptors. Four of the receptor subtypes bind $\mathrm{PGE}_{2}$ (EP1, EP2, EP3 and EP4), two bind $\mathrm{PGD}_{2}$ (DP1 and DP2), two bind TXA 2 (TP $\alpha$ and TP $\beta$ ) and the rest are single receptors for $\mathrm{PGF}_{2 \alpha}$ and $\mathrm{PGI}_{2}$ (FP and IP, respectively) (Breyer et al., 2001).

4.1.1.2. The LOX pathway. There are three major LOXs in humans: 5, 12- and 15-LOX. 5-LOX converts arachidonic acid into 5(S)- hydroxyeicosatetraenoic acid (5(S)-HETE) and LTs whereas 12- and 15-LOXs generate the corresponding 12- and 15-HETEs, respectively (Fig. 2). The best characterized and most relevant LOX is arachidonate 5-LOX. Arachidonate 5-LOX is a 674-amino acid protein, which upon cellular activation translocates to the nuclear envelope where it interacts with five lipoxygenase-activating protein (FLAP), an $18 \mathrm{kDa}$ resident integral protein which functions as a transfer protein facilitating the binding of arachidonic acid to 5-LOX (Dixon et al., 1990). In the nuclear envelope, 5-LO transforms arachidonic acid into 5(S)-HpETE, which is subsequently reduced to either 5(S)-HETE or converted to the highly unstable allylic epoxide $\mathrm{LTA}_{4}$ (Rouzer et al., 1986). Once formed, LTA 4 is rapidly transformed to either $\mathrm{LTB}_{4}$ by $\mathrm{LTA}_{4}$ hydrolase or to $\mathrm{LTC}_{4}$ by $\mathrm{LTC}_{4}$ synthase (Radmark et al., 1984). LTC $_{4}$ is subsequently deaminated into LTD $_{4}$ and $\mathrm{LTE}_{4}$ (Fig. 2). These 5-LOX products bind G-protein coupled receptors (GPCRs), in particular $\mathrm{B}-\mathrm{LT}_{1}$ and $\mathrm{B}-\mathrm{LT}_{2}$ receptors for $\mathrm{LTB}_{4}$

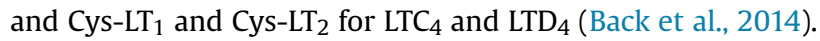

On the other hand, 15-LOX exists in two isoforms: 15-LOX-1 and 15-LOX-2, which transform arachidonic acid into 15(S)-HETE (Kuhn et al., 2015). 12/15-LOX is the murine ortholog of human 15-LOX-1 (Kuhn et al., 2015). The physiologic role of 15-LOX is dependent on the context in which it is expressed, but this pathway is essential for the formation of products able to antagonize and properly resolve inflammatory responses (see Section 4.1.3). Regarding 12-LOX, this enzyme exists in three isoforms designated after the cells in which they were first identified: platelet-type, which metabolizes arachidonic acid into 12(S)-HETE; leukocyte-type, which converts 
arachidonic acid or linoleic acid into 12(S)-HETE and also small quantities of 15(S)-HETE; and epithelial- or epidermis-type, that catalyzes the synthesis of both 12(S)- and 15(S)-HETE from arachidonic acid (Kuhn et al., 2015; Cole et al., 2013).

The interaction between individual LOX gives rise to the formation of lipoxins (LXs) by transcellular biosynthesis, eicosanoids that exert potent anti-inflammatory and immunoresolving actions in mammalian cells (Chiang et al., 2005). Three routes of transcellular LX biosynthesis have been described. The first route is initiated by the release of the epoxide intermediate $\mathrm{LTA}_{4}$ formed by 5 -LOX in activated leukocytes, which is then converted by platelet 12-LOX to $\mathrm{LXA}_{4}$ and $\mathrm{LXB}_{4}$ (Serhan and Sheppard, 1990). The second route takes place mainly in tissues in which endothelial and epithelial cells expressing 15-LOX can interact with 5-LOX-containing leukocytes (Chiang et al., 2005). Finally, a third major route of LX biosynthesis initiated by aspirin has been described (Claria and Serhan, 1995). Aspirin acetylates COX-2 and switches its catalytic activity from a PG synthase to a 15-LOX in such a way that PG biosynthesis is inhibited and arachidonic acid is instead transformed to 15(R)-HETE (Claria and Serhan, 1995). 15(R)-HETE is subsequently transformed by activated leukocytes possessing 5LOX to a new series of carbon-15 epimers of LXs that carry their 15 alcohol in the $R$ configuration (15-epi-LXs) (Claria and Serhan, 1995). The formation of these lipid mediators is specific for aspirin treatment, and the term aspirin-triggered LXs, abbreviated as AT-LXs, has been coined for these compounds (Claria and Serhan, 1995).

\subsubsection{Biosynthesis and actions of omega-6-derived lipid mediators in WAT}

The ability of WAT to generate bioactive lipid mediators was first described in the late 1960s when Shaw and Ramwell identified a group of hydroxyl C20 carboxylic acids, later identified as PGs derived from the oxygenation of arachidonic acid by COX in rat epipidymal fat pads (Shaw and Ramwell, 1968). Among the different COX-derived products, $\mathrm{PGE}_{2}$ was recognized as one of the most abundant PGs in WAT. This finding was consistent with studies pointing to $\mathrm{PGE}_{2}$ as a negative regulator of hormonestimulated lipolysis (Steinberg et al., 1963). Along these lines, preincubation of adipocytes with COX inhibitors has been reported to enhance lipolysis (Chatzipanteli et al., 1992). Given that the lipolytic actions of catecholamines are mediated by cAMP, which in turn activates HSL, the anti-lipolytic actions of $\mathrm{PGE}_{2}$ are likely associated with the modulation of adipocyte cAMP levels (Kather et al., 1985). PGE 2 has also been shown to suppress 3T3-L1 adipocyte differentiation by binding to EP4 and eliciting an increase in intracellular cAMP levels in preadipocytes (Tsuboi et al., 2004). Recently, we gathered data supporting a coordinated negative regulation between $\mathrm{PGE}_{2}$ and PPAR $\gamma$ (Garcia-Alonso et al., 2013). Indeed, mice deficient in PPAR $\gamma$ showed increased expression of COX-2 and mPGES-1 and augmented $\mathrm{PGE}_{2}$ levels, whereas the addition of exogenous $\mathrm{PGE}_{2}$ suppressed PPAR $\gamma$ expression (GarciaAlonso et al., 2013). Opposite effects were seen after the inhibition of endogenous $\mathrm{PGE}_{2}$ biosynthesis with a selective MPGES-1 inhibitor (Garcia-Alonso et al., 2013). Of note, $\mathrm{PGE}_{2}$ diverted preadipocyte differentiation to beige/brite mature adipocytes accompanied by up-regulation of UCP1, whereas a selective pharmacological mPGES-1 inhibitor and a siRNA directed against mPGES-1 resulted in the reduction of browning markers (i.e. UCP1, CIDEA and PGC-1 $\alpha$ ) and browning determination factors (i.e. PRDM16) in preadipocytes (Garcia-Alonso et al., 2013).

In addition to $\mathrm{PGE}_{2}$, it has been postulated that another COXderived product, 15 -deoxy- $\Delta^{12,14}$-prostaglandin $\mathrm{J}_{2} \quad\left(15 \mathrm{~d}-\mathrm{PGJ}_{2}\right)$, plays a relevant role in adipose tissue by regulation of the adipogenic process. $15 \mathrm{~d}-\mathrm{PGJ}_{2}$ is a cyclopentenone metabolite produced by dehydration of $\mathrm{PGD}_{2}$ (Bell-Parikh et al., 2003). The predominant enzymatic source of $15 \mathrm{~d}-\mathrm{PGJ}_{2}$ formation in vivo is COX-2, and unlike other PGs, no specific membrane receptor has been identified for this lipid mediator (Forman et al., 1995). Instead, 15d-PGJ 2 exerts its anti-inflammatory and adipogenic actions through binding and activation of the nuclear receptor PPAR $\gamma$ (Forman et al., 1995). Exposure of human adipocytes to $15 \mathrm{~d}-\mathrm{PG} \mathrm{J}_{2}$, inhibits the secretion of pro-inflammatory adipokines and stimulates the production of macrophage inhibitory cytokine- 1 , a protective adipokine, by adipose tissue (Ding et al., 2009). In addition, a significant downregulation in the expression and secretion of the proinflammatory adipokine leptin has been reported in adipocytes exposed to exogenous $15 d-\mathrm{PGJ}_{2}$ (Sinha et al., 1999). Importantly, 15d-PGJ2 stimulates adipogenesis (Sinha et al., 1999) and also exerts proadipogenic actions in fibroblasts, although in this case lymphocytes are the source of this cyclopentenone PG (Feldon et al., 2006). Surprisingly, an impaired adipogenic program has been identified in 3T3-L1 cells with stable transfection of PGD synthase and appreciably higher levels of endogenous $\mathrm{PGD}_{2}$-derived metabolites, suggesting a complex regulatory interaction between PPAR $\gamma$ and pro-adipogenic lipid mediators (Hossain et al., 2012).

Apart from COX products, WAT also has the ability to produce and release LOX products, especially $\mathrm{LTB}_{4}$, which apparently is the predominant LOX metabolite in this tissue (Horrillo et al., 2010). In this regard, WAT expresses all the enzymes necessary for the formation of 5-LOX products (5-LOX, FLAP, LTA 4 hydrolase, and LTC $_{4}$ synthase), as well as all the receptors involved in LT signaling (BLT1, BLT-2, CysLT1, and CysLT2) (Horrillo et al., 2010). LTB 4 has been identified as an inflammatory factor in WAT, and FLAP overexpression and excessive generation of 5-LOX products is a common finding in WAT of obese patients and animals with insulin resistance (Horrillo et al., 2010; Li et al., 2015; Pardo et al., 2015). Moreover, a direct relationship has been reported between LTB $_{4}$ and enhanced release of inflammatory adipokines (i.e. MCP-1 and IL-6) in obese WAT (Horrillo et al., 2010). Consistent with this finding, mice deficient in the $\mathrm{LTB}_{4}$ receptor BLT-1 show reduced monocyte recruitment to hypertrophied adipose tissue, whereas inhibition of the 5-LOX pathway with a selective FLAP inhibitor or genetic deletion of the BLT- 1 receptor alleviates adipose tissue inflammation and insulin resistance in obesity (Horrillo et al., 2010; Spite et al., 2011).

\subsubsection{Omega-3-derived lipid mediators}

EPA and DHA are the archetypal omega-3-PUFAs that are substrates of the same COX and LOX pathways described previously for omega-6-PUFA. However, in the case of EPA and DHA, they are converted into potent anti-inflammatory and pro-resolving mediators, generically known as specialized pro-resolving mediators (SPM). This family includes a number of functionally distinct mediators such as resolvins, protectins and maresins (Serhan, 2014; Serhan and Chiang, 2013). These novel bioactive lipid mediators are further classified as either resolvins of the E-series if the biosynthesis is initiated from EPA or resolvins of the D-series if they are generated from DHA (Serhan et al., 2000). Protectins and maresins are also biosynthesized from DHA (Serhan et al., 2006, 2009). A schematic diagram of DHA and EPA-derived lipid mediators is shown in Fig. 3. The biosynthesis of omega-3-derived lipid mediators and their role in the metabolic syndrome and related liver disease have been described in detail in a recent review by our group (Lopez-Vicario et al., 2015a).

\subsubsection{Biological actions of omega-3-derived lipid mediators in WAT}

Human and mouse WAT express all the enzymes necessary for the biosynthesis of resolvins, protectins and maresins derived from omega-3 PUFAs, as well as all the receptors necessary for their 


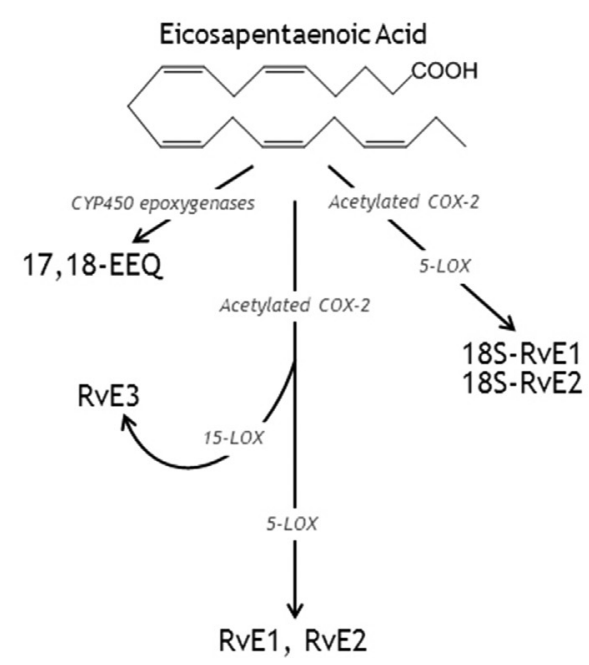

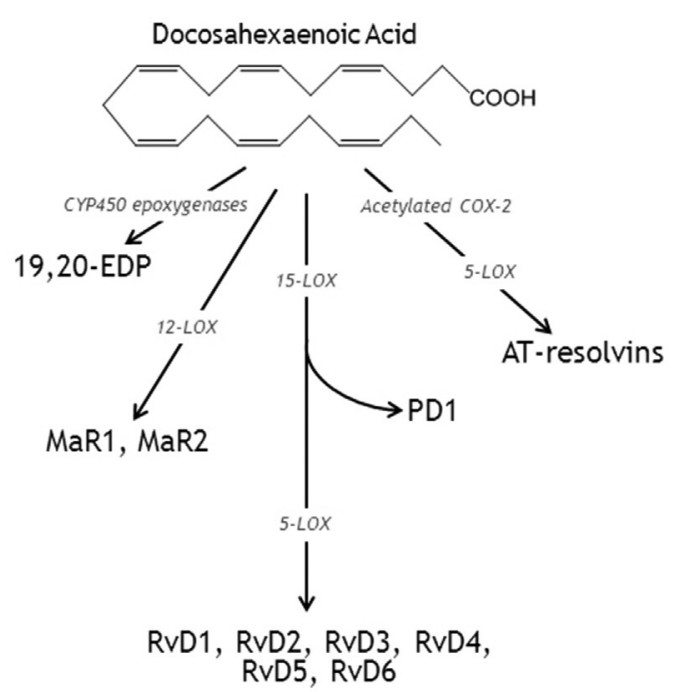

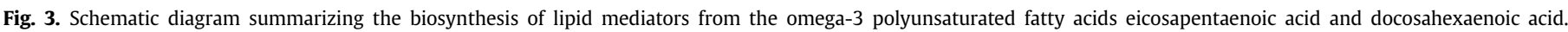

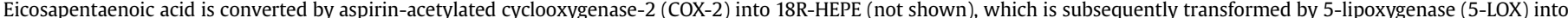

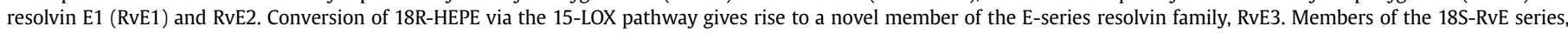

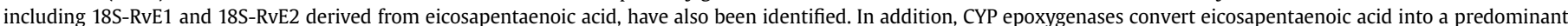

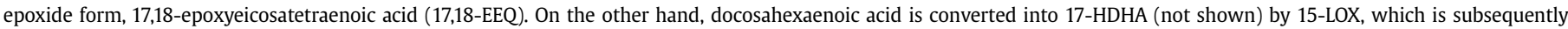

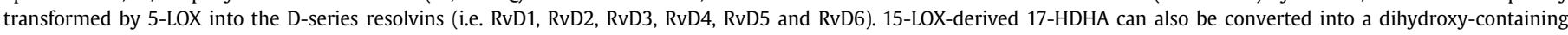

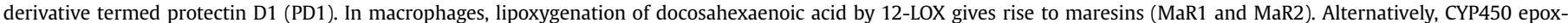

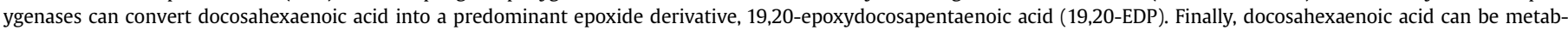
olized by aspirin-acetylated COX-2 and 5-LOX into the so-called aspirin-triggered (AT)-resolvins.

signaling (reviewed in (Spite et al., 2014)). In the setting of obesity, prevailing data support an unbalanced formation of these omega3-derived lipid mediators in obese WAT. Indeed, a deficit in tissue SPM levels (RvD1, PD1 and 17-HDHA) has been characterized in inflamed visceral and subcutaneous fat compartments from obese $o b / o b$ and obese/diabetic $d b / d b$ mice (Gonzalez-Periz et al., 2009; Claria et al., 2012; Neuhofer et al., 2013). In humans, a deficit in PD1 and its precursor 17S-HDHA has been reported in subcutaneous fat from patients with peripheral vascular disease in whom the inflammatory status in adipose tissue is remarkably exacerbated compared with healthy subcutaneous fat (Claria et al., 2013). Moreover, LC-MS/MS-based metabolo-lipidomic analyses of fat from selected human anatomic locations have identified unique signature profiles in the content of bioactive lipids (Claria et al., 2013). Importantly, these analyses demonstrated a heterogeneous capacity for SPM biosynthesis among different adipose tissue depots, with higher activation of resolution circuits in perivascular fat compared with subcutaneous fat (Claria et al., 2013). This is relevant for vascular pathologies, with perivascular adipose tissue playing an emerging role in vascular biology homeostasis because of its tissue mass and anatomic proximity surrounding systemic vessels.

The compromised capacity to produce local SPM in obese tissues with a heightened pro-inflammatory phenotype could be the consequence of a structural deficiency in the tissue content of omega-3-PUFAs as established substrates for SPM biosynthesis. Indeed, there is evidence that SPM are generated in humans taking omega-3 dietary supplements and that SPM levels are increased above those produced normally in transgenic fat-1 mice (Hudert et al., 2006). This is consistent with the observation that transgenic restoration of omega- 3 fatty acids in fat-1 mice with high-fat diet (HFD)-induced obesity reversed their inefficient resolution capacity and produced anti-inflammatory and pro-resolution actions in adipose tissue (Lopez-Vicario et al., 2015b; White et al., 2010). Alternatively, the loss of SPM in obesity may reflect accelerated tissue SPM conversion and clearance to inactive further metabolites because 15-PG-dehydrogenase/eicosanoid oxidoreductase, the key enzyme in SPM inactivation, is markedly upregulated in obese adipose tissue (Claria et al., 2012). In this tissue, omega-3-derived SPM are readily converted metabolically into oxo-resolvin products, some of which are biologically inactive (Claria et al., 2012). In addition, sEH, the enzyme that catalyzes the rapid hydrolysis of omega- 6 and omega- 3 epoxides by converting them into inactive or less active diols is invariably over-expressed in HFD-induced obese mice (Lopez-Vicario et al., 2015b). Collectively, these findings are consistent with the notion that unresolved chronic inflammation in obese adipose tissue is the result of an inappropriate SPM resolution-capacity allowing the inflammatory response to proceed without controlled checkpoints.

The use of synthetic SPM in different in vivo, ex vivo, and in vitro studies has provided clues of the role of SPM in adipose tissue homeostasis. In this regard, the administration of nanogram amounts of RvD1 to obese/diabetic $d b / d b$ mice improves glucose tolerance, decreases fasting blood glucose, and increases insulinstimulated Akt phosphorylation in adipose tissue (Hellmann et al., 2011). This SPM also reduces the formation of macrophagecontaining crown-like structures in adipose tissue (Hellmann et al., 2011). Similarly, intraperitoneal injection (nanogram amounts) of RvE1 to obese ob/ob mice confers significant insulinsensitizing effects by mechanisms related to the AMPKadiponectin axis and the induction of GLUT-4 and IRS-1 expression (Gonzalez-Periz et al., 2009). In addition, 17S-HDHA treatment (intraperitoneal injection of nanogram doses) reduces adipose tissue expression of inflammatory cytokines (MCP-1, TNF $\alpha$, IL-6 and osteopontin), increases adiponectin expression and improves glucose tolerance in parallel with insulin sensitivity in obese/diabetic $d b / d b$ mice (Neuhofer et al., 2013). Similar beneficial actions in adipose tissue physiology have been described for $\mathrm{LXA}_{4}$ in an experimental model of adipose tissue inflammation associated with aging (Borgeson et al., 2012). Ex vivo, in fat explants, both RvD1 and RvD2 rescue the impaired phenotype of obese adipose tissue by enhancing the expression and secretion of adiponectin in 
parallel with decreasing the secretion of pro-inflammatory adipokines/cytokines including leptin, TNF $\alpha$, IL-6 and IL-1 $\beta$ (Claria et al., 2012). In vitro, nanomolar concentrations of RvD1 stimulate macrophage nonphlogistic phagocytosis, a critical process in the resolution of inflammation, and enhance the phagocytic activity of macrophages isolated from the adipose tissue stromal vascular cell fraction (Titos et al., 2011). In human monocyte-adipocyte co-incubations, both RvD1 and RvD2 reduce MCP-1 and $\mathrm{LTB}_{4}$-stimulated monocyte adhesion to adipocytes as well as monocyte transadipose migration, which are critical for the recruitment of monocytes/ macrophages into the inflamed adipose tissue (Claria et al., 2012).

In line with SPM-protective actions against excessive macrophage recruitment, RvD1 skews polarization of adipose tissue macrophages from a classical activation inflammatory profile (M1 phenotype) toward an alternative anti-inflammatory M2like state (Titos et al., 2011). This phenotypic switch is characterized by a reduction of secreted pro-inflammatory adipokines, such as TNF $\alpha$ and IL-6 accompanied by an up-regulation of a complete panel of M2 markers including IL-10, CD206, RELM- $\alpha$ and Ym1 (Titos et al., 2011). In addition, RvD1 remarkably increases arginase-1 expression, a well-established M2 marker, while attenuating IFN $\gamma /$ LPS-induced Th1 cytokine secretion (Titos et al., 2011). Of particular interest, changes in the expression of M1/M2 markers appear to be confined to the adipose tissue stromal vascular fraction, which is highly populated by macrophages (Titos et al., 2011). These results are in agreement with those reported by Hellmann et al. (2011), who showed the ability of RvD1 to improve insulin resistance in obese-diabetic mice by reducing macrophage $\mathrm{F} 4 / 80^{+} \mathrm{CD} 11 \mathrm{c}^{+}$cell accumulation and increasing the percentage of $\mathrm{F} 4 / 80^{+}$cells expressing the $\mathrm{M} 2$ marker Mgl-1 in adipose tissue. The switch of recruited macrophages toward a M2 phenotype is interpreted as antiinflammatory and pro-resolving (Olefsky and Glass, 2010). Of particular interest is the fact that when leukocytes exit the inflamed site or exudate, they traverse perinodal adipose tissue en route to local lymph nodes (Schwab et al., 2007). Excessive and persistent inflammation during this lipo-passage or failure of leukocytes to reach the lymphatics and hence, getting stuck while activated within adipose, can lead to adipose inflammation that may contribute to the metabolic syndrome. Finally, in a recent study, we used fat-1 mice as an optimal model of omega-3 tissue enrichment, in which the stabilization of the CYP-derived 19,20-EDP epoxide by a sEH inhibitor down-regulated obesityinduced ER stress and autophagy in adipose tissue (Lopez-Vicario et al., 2015b). Since inhibition of autophagic function in adipose tissue is related to reduced fat mass and improved insulin sensitivity (Singh et al., 2009), these findings can be regarded as beneficial in terms of lipid homeostasis and metabolic control.

Apart from adipose tissue, SPM also exert beneficial roles in other insulin-sensitive tissues such as the liver. Indeed, hepatocytes from transgenic fat-1 mice, which have increased levels of resolvins, and wild-type hepatocytes incubated with nanomolar concentrations of RvD1, show a reduction in neutral lipid accumulation (steatosis) as well as inflammation (Lopez-Vicario et al., 2015b, 2014). In addition, PD1 and 17S-HDHA are able to attenuate DNA damage and oxidative stress in hepatocytes and reduce $\mathrm{TNF} \alpha$ release in macrophages (Gonzalez-Periz et al., 2006), whereas LXA $_{4}$ and AT-LXA 4 efficiently block IL-8 secretion by hepatocytes (Planaguma et al., 2002). Moreover, in precision-cut liver slices, an ex vivo model that overrides the influence of extrahepatic circulating factors, Rius and collaborators have demonstrated that RvD1 reduces hypoxia-induced mRNA and protein expression for inflammatory genes including COX-2, IL$1 \beta$, IL-6 and CCR7 (Rius et al., 2014). Of interest, the antiinflammatory actions of RvD1 were completely absent in tissue slices in which macrophages were depleted with chlodronate liposomes (Rius et al., 2014), a finding that highlights the critical role of macrophages in the resolution phase of inflammatory response. Finally, the DHA derived 19,20-EDP epoxide was shown to restore autophagy in hepatocytes with the subsequent reduction of ER stress in these liver cells (Lopez-Vicario et al., 2015b). In summary, these findings highlight the potential of small bioactive lipid mediators to not only modulate lipid homeostasis and inflammation in insulin sensitive tissues, but also to serve as templates for the exploitation of cellular housekeeping processes (i.e. autophagy) in therapeutic interventions against obesityrelated hepatic co-morbidities.

\section{2. $D A G$}

Diacylglycerol (DAG) biosynthesis is initiated from glycerol-3phosphate generated by glycolysis in the cytoplasm of liver or adipose tissue cells (Li et al., 2010). Glycerol-3-phosphate is acylated with acyl-CoA to form lysophosphatidic acid (LPA), which is again acylated to give phosphatidic acid (PA). Subsequently, PA dephosphorylation forms DAG (Li et al., 2010). DAG is the precursor of TAG which is generated by another acylation catalyzed by diglyceride acyltransferase. This synthetic pathway can be reversed, and by the action of lipases (ATGL or HSL) TAG is hydrolyzed to DAG. Moreover, phospholipase C (PLC) can directly release DAG from phospholipids, by a hydrolytical reaction between the phosphate and the glycerol backbone (Gresset et al., 2012). All these reactions give rise to the 1,2 or the 2,3 DAG isoform; however, in some edible oils DAG can be found as a minor constituent in its 1,3 isoform, which is produced during high temperature, manufacturing processes (Flickinger and Matsuo, 2003). PLC can generate DAG from phosphatidylinositol 4,5-bisphosphate (PIP2) hydrolysis. This reaction releases inositol triphosphate (IP3) to the cytosol (Gresset et al., 2012), which stimulates calcium release. On the other hand, DAG is hydrophobic and remains in the membrane, acting as a signal messenger for activation of protein kinase $C$ (PKC), and facilitates its translocation to the cellular membrane. DAG-mediated PKC activation in adipocytes through $\beta$-adrenergic receptors, in turn, increases glycogenolysis and gluconeogenesis (Lafontan et al., 1997).

Compared with TAG oils, dietary DAG oils suppress postprandial hypertriglyceridemia and decrease body fat mass (Nagao et al., 2000; Yamamoto et al., 2006). In animal studies this anti-obesity effect was attributed to an increase in $\beta$-oxidation of fatty acids, major energy expenditure and suppression of TAG synthesis (Meng et al., 2004; Kimura et al., 2006; Murase et al., 2001). DAG enriched structural lipids containing conjugated linoleic acid and capric acid (a medium chain fatty acid, MCFA) given in the diet to Sprague-Dawley rats, lowered the concentration of plasma TAG and decreased fat pads, simultaneously enhancing lipoprotein lipase activity (Kim et al., 2006). On the other hand, dietary supplementation with $\alpha$-linoleic acid-rich DAG induced the up-regulation of $\beta$ oxidation of fatty acids, resulting in reduced body weight and fatty liver (Murase et al., 2002, 2005). For further information on this class of lipids see reference (Finck and Hall, 2015).

\subsection{Endocannabinoids}

The endocannabinoid system is involved in the regulation of WAT metabolism, energy homeostasis and appetite. The two classical endocannabinoids are anandamide (AEA) and 2arachidonoglycerol (2-AG), both derived from the omega-6-PUFA arachidonic acid (sn-1 and sn-2 positions for AEA and 2-AG, respectively) (Bab et al., 2009). Three routes for AEA synthesis have been described. The major route is by arachidonic acid cleavage 
from phosphatidylethanolamine and involves an acyltransferase and a specific phospholipase D (Fezza et al., 2005). The second route includes the action of phospholipase $C$ and the formation of a phosphorylated intermediate that is then hydrolyzed by a phosphatase to form AEA. A third route involving arachidonic acid and ethanolamine condensation pathway has been described. The enzyme fatty acid amide hydrolase is a reversible enzyme that normally cleaves AEA to AA and ethanolamine, but it can also catalyze the AA and ethanolamide condensation into AEA. Three pathways have been described for 2-AG synthesis. It can be synthesized from phosphatidylinositol hydrolysis by phospholipase A that yields lysophosphatidylinositol, that is further hydrolyzed by phospholipase $C$ to produce 2-AG. A second pathway involves phospholipase $C$ action generating DAG with $A A$ in its composition, which is further hydrolyzed by DAG lipase releasing 2-AG. The third pathway for 2-AG formation is catalyzed by a monoacylglycerol kinase acting over 2-arachidonoyl lysophosphatidic acid forming 2AG (Sugiura et al., 1995).

Endocannabinoids exert their functions by binding to two cannabinoid receptors: CB-1 and CB-2 (Nogueiras et al., 2009). Apart from regulating appetite, and thus food intake, endocannabinoids participate in the control of lipid and glucose metabolism, and its dysregulation in obesity contributes to fat accumulation and associated metabolic disorders (Bluher et al., 2006; Di Marzo, 2008). Circulating levels of 2-AG are increased in obese compared to lean individuals (Bluher et al., 2006; Cote et al., 2007), and their levels are correlated with BMI and intra-abdominal adiposity (Cote et al., 2007; Cable et al., 2011). The expression of the CB-1 receptor is also correlated with BMI and the metabolic syndrome (Sarzani et al., 2009). Overall the endocannabinoid system is dysregultaed in peripheral tissues in obesity, altering lipid and glucose metabolism (Pagano et al., 2007; You et al., 2011; Izzo et al., 2009). In visceral adipose tissue there is greater mRNA expression of CB-1 than in subcutaneous adipose tissue (Bluher et al., 2006). Moreover, in obese individuals, 2-AG, CB-1 and MGL are up-regulated in abdominal adipose tissue, whereas their expression is downregulated in gluteal adipose tissue (Pagano et al., 2007; You et al., 2011). Collectively, current evidence indicates that the endocannabinoid system is dysregulated in obesity and greatly influences the storage of energy in different adipose tissue depots. For further information on endocannabinoids see reference (Silvestri and Di Marzo, 2013).

\subsection{Nitroalkenes of fatty acids}

Nitro fatty acids are formed by nitration of unsaturated fatty acids. For this process, the formation of $\cdot \mathrm{NO}_{2}$ during gastric acidification or in the presence of nitric oxide $(\cdot \mathrm{NO})$ and nitrite $\left(\mathrm{NO}_{2}{ }^{-}\right)$is necessary (Bonacci et al., 2012). The nitration of PUFAs results in the formation of electrophilic fatty acid nitroalkene derivatives (NO2FA) with biological properties including nitro-oleic acid (NO2$\mathrm{OA}$ ), nitro-linoleic acid (NO2-LA) and nitro-conjugated linoleic acid (NO2-CLA). NO2-FAs have been detected in plasma and urine from healthy subjects at nano-to micromolar concentrations (Baker et al., 2005; Khoo and Freeman, 2010; Schopfer et al., 2011). Transcriptional responses to NO2-FAs account for a broader array of signaling events than fatty acid derivatives generated by enzymatic oxygenation (Rudolph and Freeman, 2009; Kansanen et al., 2009). This is due to the pleiotropic effects of the Michael addition reaction by which the electrophilic NO2-FAs can react with the nucleophilic center of a protein (for example a cysteine or histidine residue) that regulates their structure, function and subcellular distribution (Schopfer et al., 2010).

NO2-OAs display anti-inflammatory properties in vitro and in vivo. Indeed, NO2-OAs limit LPS-induced inflammation and multi-organ dysfunction and have a reduced expression of MCP-1, intercellular adhesion molecule-1, vascular cell adhesion molecule-1, xanthine oxidase, inducible NO synthase and COX-2 (Wang et al., 2010a; Kelley et al., 2008). NO2-FAs have been reported to inhibit NF- $\kappa \mathrm{B}-$ regulated gene expression, as a consequence of adduction of a cysteine in the p65 subunit (Cui et al., 2006). NO2-FAs also mediate the adduction of a cysteine residue in Keap1, an Nrf2 regulatory protein, activating Nrf2-dependent phase 2 gene expression, thereby protecting the cells against oxidative damage and inflammation (Kansanen et al., 2009). NO2-FAs can regulate glucose and lipid metabolism by binding to PPAR $\gamma$ (Li et al., 2008; Schopfer et al., 2005). Recently, $\mathrm{NO}_{2}-\mathrm{FAs}$ were reported to inactivate the 5-LOX enzyme, resulting in a lower production of inflammatory eicosanoids (Awwad et al., 2014). More recently, Kelley et al. have reported that $\mathrm{NO}_{2}-\mathrm{FAs}$ improve glucose tolerance and reduce the expression of inflammatory cytokines and circulating leptin levels while increasing adiponectin in a HFD model of obesity (Kelley et al., 2014). In a previous study, Wang and collaborators administered $\mathrm{NO}_{2}-\mathrm{OA}$ to obese Zucker rats to reduce body weight, TAG and FFA levels, and TBARS and proteinuria (Wang et al., 2010b). For further information on this class of lipids see reference (Rubbo, 2013; Narala et al., 2014).

\subsection{Fatty acid-hidroxy fatty acids (FAHFA)}

A new class of fatty acid derivatives designated as FAHFA has recently been identified by Yore et al. (2014). In WAT, these lipid mediators are synthesized in response to carbohydrate-responsive element-binding protein (ChREBP) and released to the blood, enhancing insulin secretion and glucose uptake (Yore et al., 2014). These authors identified FAHFA in adipose tissue of AG4OX mice, a transgenic model of Glut-4 over-expression, using an untargeted mass spectrometry lipidomic approach. Among the 16 species of FAHFA identified, palmitic acid-hydroxy stearic acid (PAHSA) was the most up-regulated. Eight isomers of this branched fatty acid (depending on the carbon position of the ester) were detected, among which the most relevant were 5- and 9-PAHSA (Yore et al., 2014). In this study, PAHSA levels were reduced in mice and humans with obesity and insulin resistance, and oral administration of 5- and 9-PAHSA was able to enhance glucose tolerance (Yore et al., 2014). Additionally, PAHSA increased Glp-1 secretion in intestinal enteroendocrine cells and enhanced pancreatic insulin secretion. Apart from these metabolic effects, PAHSA exhibited anti-inflammatory properties (Yore et al., 2014). Apparently, PAHSA exert all the above-described biological activities by binding to the long-chain fatty acid receptor GPR120 (Yore et al., 2014). Nonetheless, it remains unclear whether FAHFA biosynthesis is limited to adipocytes or it is produced in other tissues as well.

\subsection{Sphingolipids}

Sphingolipids contain a backbone of sphingosine and other aliphatic amino alcohols. Sphingolipids play different roles in the cell as structural lipids of the cell membrane by forming a stable and chemically resistant outer protective layer as well as in cell recognition and intracellular signaling. Ceramide is released from the hydrolysis of sphingomyelin (located in the cell membrane), which in turn can be converted to sphingosine and sphingosine-1phosphate (S1P) (Fig. 1). Both ceramide and S1P are involved in different signaling cascades that participate in proliferation, differentiation, senescence, stress response, necrosis, apoptosis, autophagy, and inflammation.

Apart from the mentioned hydrolytic formation of ceramide from sphingomyelin by the action of acid or neutral SMases 
(Hannun and Obeid, 2008), ceramide can be biosynthesised de novo. In this case, ceramide biosynthesis is initiated by the condensation of serine and palmityl $\mathrm{CoA}$ by serine palmitoyltransferase, and subsequent actions of 3-ketosphinganine reductase, ceramide synthase and dihydroceramide desaturase. Alkaline or acid ceramidase deacetylates ceramide to generate sphingosine, and sphingosine kinase phosphorylates sphingosine to S1P. Similarly, ceramide kinase phosphorylates ceramide to ceramide 1 phosphate (C1P) (Sugiura et al., 2002). The availability of free fatty acids and inflammatory cytokines increases ceramide synthesis (Samad et al., 2006; Schilling et al., 2013), suggesting that ceramide metabolism may be altered in obesity. In obese rodents and humans ceramide is elevated in the liver, the hypothalamus and skeletal muscle (Adams et al., 2004; Holland et al., 2007). In leptindeficient ob/ob mice, total sphingomyelin and ceramide levels in adipose tissue are reduced, whereas circulating levels of sphingomyelin, ceramide, sphingosine and S1P are increased in plasma, since ceramide secretion by adipose tissue is increased (Samad et al., 2006). In addition, the inflammatory status associated with obesity overlaps with ceramide production. TNF- $\alpha$ administration to mice results in an up-regulation of ceramide synthetic enzymes in adipose tissue, thus increasing ceramide production (Samad et al., 2006).

Adiponectin, the levels of which are generally reduced in obesity and diabetes (Liu et al., 2007), is linked to sphingolipid metabolism. The receptors for adiponectin contain ceramidase activity, thereby reducing ceramide levels (Holland et al., 2011), an activity that depends on adiponectin levels and binding to the receptors. This ceramidase activity leads to the release of a fatty acid and sphingosine that can be phosphorylated to S1P which has anti-apoptotic and anti-diabetic effects. S1P is released and through S1P receptors elevates intracellular calcium and activates AMPK, which participates in FA oxidation (Fang and Sweeney, 2006; Matsuzawa, 2010), thus alleviating lipotoxicity and reducing metabolic dysregulation. Moreover, adiponectin transgenic mice have better insulin tolerance under a HFD (Luo et al., 2010).

Obesity is associated with insulin resistance and type 2 diabetes. Ceramide appears to be elevated in these conditions, correlating positively with the degree of insulin resistance (Haus et al., 2009). In vitro, ceramide and sphingosine can inhibit insulin signaling by inhibiting Akt and AMPK (Hajduch et al., 2001; Liu et al., 2004; Summers, 2006). In vivo, the administration of myoricin, a serine palmitoyltransferase inhibitor, results in an improvement in insulin resistance in different disease models due to the inhibition of de novo ceramide biosynthesis (Holland et al., 2007). Heterozygous deficiency of dihydroceramide desaturase, another protein of the ceramide synthetic pathway, results in improved insulin sensitivity, and protection against dexamethasone-induced insulin-resistance (Holland et al., 2007). In 3T3-L1 adipocytes, ceramide blocks the phosphorylation of Akt and IRS-1 (Summers et al., 1998; Chavez et al., 2003); activates protein phosphatase 2A and PKC $\xi$; and inhibits Akt translocation to the membrane (Powell et al., 2003, 2004). In NAFLD patients, ceramide biosynthesis and levels are also significantly increased (Kolak et al., 2007). Moreover, in ob/ob mice hepatic ceramide levels correlated with the degree of steatosis (Kolak et al., 2007). For further information on this class of lipids see reference (Hla and Dannenberg, 2012; Larsen and Tennagels, 2014).

\subsection{Short- and medium-chain fatty acids}

Short-chain fatty acids (SCFA) and MCFA are not generated within adipose tissue and are generally derived from fiber fermentation in the colon. These fatty acids enter the blood directly through the portal vein during lipid digestion, as opposed to long chain fatty acids which require proper absorption into the blood circulation (Papamandjaris et al., 1998). An important feature of SCFA and MCFA is that they remarkably differ in the number of carbons. In this regard, MCFA contain 8-10 carbon atoms, as in caprylic (C8:0) and capric (C10:0), whereas SCFA contain less than 8 carbons in their structure. Relevant members of the SCFA are formic acid, acetic acid, propionic acid, butyric acid and valeric acid, among others. Among these, butyric acid is the best known for its biological functions. Butyric acid is a substrate for growth and regeneration of cells in the large intestine; it has anti-cancer properties in colon cancer, probably enhancing apoptosis of tumoral cells, and more importantly for the purpose of this review, it increases thermogenesis, energy expenditure and contributes to the reduction of body weight and other factors present in the metabolic syndrome (Goncalves and Martel, 2013; Liu et al., 2011; Xue et al., 2009).

\section{Concluding remarks}

Much progress has been made in identifying some of the triggers of adipose tissue inflammation in obesity. Among the factors that are involved in this uncontrolled "low-grade" inflammatory response, lipid mediators play a pivotal role. Indeed, a number of lipid mediators derived from membrane phospholipids, including PUFA derivatives, are emerging as key regulators of adipose tissue homeostasis. Any strategy targeting mediators of inflammation such as omega-6 derivatives (i.e. PGs and LTs) and sphingolipids (i.e. LPA, S1P and ceramide) would be beneficial in reducing obesity-associated comorbidities. Another strategy to combat inflammation in adipose tissue is based on fostering the endogenous production of anti-inflammatory and pro-resolving mediators derived from omega-3 fatty acids, such as resolvins, protectins and maresins. Alternatively, the exogenous administration of stable analogs of this novel functional set of lipid autacoids would promote the timely resolution of inflamed tissues.

Interestingly, other fatty acid-derived molecules have come into focus in the last few years, giving us more tools to regulate obesity-related metabolic diseases. For example, nitroalkene derivatives such as nitro-oleic acid have been reported to exert pleiotropic effects, which overall reduce the inflammatory state and improve glucose tolerance. Another example is the recently identified fatty acid hydroxy fatty acids described by Yore et al. in adipose tissue. These authors have reported some metabolic effects of these novel lipids, such as enhanced glucose tolerance, and anti-inflammatory actions. Nonetheless, more studies are needed to demonstrate their potential. However, not only have these novel lipids opened and expanded new avenues in the field of lipid mediators, but they have also encouraged the search for new therapeutic molecules, thereby providing more options for the pharmacological regulation of obesity related diseases.

In summary, the current review provides up-to-date insight on the wide variety of lipid mediators present in mammalian cells, with special emphasis on the role of these bioactive lipids in the regulation of adipose tissue homeostasis.

\section{Acknowledgments}

This work was conducted at the Esther Koplowitz Center and was supported by Ministerio de Economía y Competitividad (MEC) (SAF12/32789 and PIE14/00045) co-funded by EU FEDER resources. CIBERehd is funded by the Instituto de Salud Carlos III. Our Research Group is recognized by the Generalitat de Catalunya (2014 SGR 428). A.L. has been the recipient of an IDIBAPS Postdoctoral 
Fellowship-BIOTRACK, supported by the European Community's Seventh Framework Programme (EC FP7/2007-2013) under the grant agreement number 229673. V.G.-A. and C.L.-V. were supported by IDIBAPS/Fundació Clínic. B.R. has a FPI fellowship from MEC (bes-2013-063705), and J.A.-Q. is the recipient of a Emili Letang fellowship (HC) and a FI-AGAUR 2015 fellowship (FI_B00104). The authors are grateful to the graphic artist Pere Lluís León for excellent assistance with the illustration of Fig. 1. The authors apologize to our many colleagues whose work could not be cited due to space limitations.

\section{References}

Adams 2nd, J.M., Pratipanawatr, T., Berria, R., Wang, E., DeFronzo, R.A., Sullards, M.C., Mandarino, L.J., 2004. Ceramide content is increased in skeletal muscle from obese insulin-resistant humans. Diabetes 53, 25-31.

Alcedo, J., Noll, M., 1997. Hedgehog and its patched-smoothened receptor complex: a novel signalling mechanism at the cell surface. Biol. Chem. 378, 583-590.

Angulo, P., 2002. Nonalcoholic fatty liver disease. N. Engl. J. Med. 346, 1221-1231. http://dx.doi.org/10.1056/NEJMra011775.

Astudillo, A.M., Balgoma, D., Balboa, M.A., Balsinde, J, 2012. Dynamics of arachidonic acid mobilization by inflammatory cells. Biochim. Biophys. Acta 1821, 249-256. http://dx.doi.org/10.1016/j.bbalip.2011.11.006.

Awwad, K., Steinbrink, S.D., Fromel, T., Lill, N., Isaak, J., Hafner, A.K., Roos, J., Hofmann, B., Heide, H., Geisslinger, G., Steinhilber, D., Freeman, B.A., Maier, T.J., Fleming, I., 2014. Electrophilic fatty acid species inhibit 5-lipoxygenase and attenuate sepsis-induced pulmonary inflammation. Antioxid. Redox Signal. 20, 2667-2680. http://dx.doi.org/10.1089/ars.2013.5473.

Bab, I., Zimmer, A., Melamed, E., 2009. Cannabinoids and the skeleton: from marijuana to reversal of bone loss. Ann. Med. 41, 560-567. http://dx.doi.org/ $10.1080 / 07853890903121025$.

Back, M., Powell, W.S., Dahlen, S.E., Drazen, J.M., Evans, J.F., Serhan, C.N., Shimizu, T., Yokomizo, T., Rovati, G.E., 2014. Update on leukotriene, lipoxin and oxoeicosanoid receptors: IUPHAR review 7. Br. J. Pharmacol. 171, 3551-3574. http:// dx.doi.org/10.1111/bph.12665.

Bagga, D., Wang, L., Farias-Eisner, R., Glaspy, J.A., Reddy, S.T., 2003. Differential effects of prostaglandin derived from omega- 6 and omega- 3 polyunsaturated fatty acids on COX-2 expression and IL-6 secretion. Proc. Natl. Acad. Sci. U. S. A. 100, 1751-1756. http://dx.doi.org/10.1073/pnas.0334211100.

Baker, P.R., Lin, Y., Schopfer, F.J., Woodcock, S.R., Groeger, A.L., Batthyany, C., Sweeney, S., Long, M.H., Iles, K.E., Baker, L.M., Branchaud, B.P., Chen, Y.E., Freeman, B.A., 2005. Fatty acid transduction of nitric oxide signaling: multiple nitrated unsaturated fatty acid derivatives exist in human blood and urine and serve as endogenous peroxisome proliferator-activated receptor ligands. J. Biol. Chem. 280, 42464-42475. http://dx.doi.org/10.1074/ jbc.M504212200.

Balsinde, J., Dennis, E.A., 1997. Function and inhibition of intracellular calciumindependent phospholipase A2. J. Biol. Chem. 272, 16069-16072.

Balsinde, J., Balboa, M.A., Dennis, E.A., 1997. Inflammatory activation of arachidonic acid signaling in murine P388D1 macrophages via sphingomyelin synthesis. J. Biol. Chem. 272, 20373-20377.

Barba, G., Harper, F., Harada, T., Kohara, M., Goulinet, S., Matsuura, Y., Eder, G., Schaff, Z., Chapman, M.J., Miyamura, T., Brechot, C., 1997. Hepatitis C virus core protein shows a cytoplasmic localization and associates to cellular lipid storage droplets. Proc. Natl. Acad. Sci. U. S. A. 94, 1200-1205.

Beckers, L., Heeneman, S., Wang, L., Burkly, L.C., Rousch, M.M., Davidson, N.O., Gijbels, M.J., de Winther, M.P., Daemen, M.J., Lutgens, E., 2007. Disruption of hedgehog signalling in ApoE -/- mice reduces plasma lipid levels, but increases atherosclerosis due to enhanced lipid uptake by macrophages. J. Pathol. 212, 420-428. http://dx.doi.org/10.1002/path.2193.

Bell-Parikh, L.C., Ide, T., Lawson, J.A., McNamara, P., Reilly, M., FitzGerald, G.A., 2003. Biosynthesis of 15-deoxy-delta12,14-PGJ2 and the ligation of PPARgamma. J. Clin. Invest. 112, 945-955. http://dx.doi.org/10.1172/JCI18012.

Bluher, M., Engeli, S., Kloting, N., Berndt, J., Fasshauer, M., Batkai, S., Pacher, P., Schon, M.R., Jordan, J., Stumvoll, M., 2006. Dysregulation of the peripheral and adipose tissue endocannabinoid system in human abdominal obesity. Diabetes 55, 3053-3060. http://dx.doi.org/10.2337/db06-0812.

Bonacci, G., Baker, P.R., Salvatore, S.R., Shores, D., Khoo, N.K., Koenitzer, J.R., Vitturi, D.A., Woodcock, S.R., Golin-Bisello, F., Cole, M.P., Watkins, S., St Croix, C., Batthyany, C.I., Freeman, B.A., Schopfer, F.J., 2012. Conjugated linoleic acid is a preferential substrate for fatty acid nitration. J. Biol. Chem. 287, 44071-44082. http://dx.doi.org/10.1074/jbc.M112.401356.

Borgeson, E., McGillicuddy, F.C., Harford, K.A., Corrigan, N., Higgins, D.F., Maderna, P., Roche, H.M., Godson, C., 2012. Lipoxin A4 attenuates adipose inflammation. FASEB J. 26, 4287-4294. http://dx.doi.org/10.1096/fj.12-208249.

Bozza, P.T., Viola, J.P., 2010. Lipid droplets in inflammation and cancer. Prostagl. Leukot. Essent. Fat. Acids 82, 243-250. http://dx.doi.org/10.1016/ j.plefa.2010.02.005.

Brasaemle, D.L., 2007. Thematic review series: adipocyte biology. The perilipin family of structural lipid droplet proteins: stabilization of lipid droplets and control of lipolysis. J. Lipid Res. 48, 2547-2559. http://dx.doi.org/10.1194/ jlr.R700014-JLR200.

Breyer, R.M., Bagdassarian, C.K., Myers, S.A., Breyer, M.D., 2001. Prostanoid receptors: subtypes and signaling. Annu. Rev. Pharmacol. Toxicol. 41, 661-690. http://dx.doi.org/10.1146/annurev.pharmtox.41.1.661.

Buhman, K.K., Chen, H.C., Farese Jr., R.V., 2001. The enzymes of neutral lipid synthesis. J. Biol. Chem. 276, 40369-40372. http://dx.doi.org/10.1074/ jbc.R100050200.

Cable, J.C., Tan, G.D., Alexander, S.P., O'Sullivan, S.E., 2011. The activity of the endocannabinoid metabolising enzyme fatty acid amide hydrolase in subcutaneous adipocytes correlates with BMI in metabolically healthy humans. Lipids Health Dis. 10, 129. http://dx.doi.org/10.1186/1476-511X-10-129.

Calder, P.C., 2006. Polyunsaturated fatty acids and inflammation. Prostagl. Leukot. Essent. Fat. Acids 75, 197-202. http://dx.doi.org/10.1016/j.plefa.2006.05.012.

Cantafora, A., Blotta, I., 1996. Neutral lipids production, transport, utilization. Anticancer Res. 16, 1441-1449.

Cao, F., Castrillo, A., Tontonoz, P., Re, F., Byrne, G.I., 2007. Chlamydia pneumoniae-induced macrophage foam cell formation is mediated by Toll-like receptor 2. Infect. Immun. 75, 753-759. http://dx.doi.org/10.1128/IAI.01386-06.

Cardona, P.J., Llatjos, R., Gordillo, S., Diaz, J., Ojanguren, I., Ariza, A., Ausina, V., 2000. Evolution of granulomas in lungs of mice infected aerogenically with Mycobacterium tuberculosis. Scand. J. Immunol. 52, 156-163.

Carmen, G.Y., Victor, S.M., 2006. Signalling mechanisms regulating lipolysis. Cell Signal. 18, 401-408. http://dx.doi.org/10.1016/j.cellsig.2005.08.009.

Chandrasekharan, N.V., Simmons, D.L., 2004. The cyclooxygenases. Genome Biol. 5 , 241. http://dx.doi.org/10.1186/gb-2004-5-9-241.

Chatzipanteli, K., Rudolph, S., Axelrod, L., 1992. Coordinate control of lipolysis by prostaglandin E2 and prostacyclin in rat adipose tissue. Diabetes 41, 927-935.

Chavez, J.A., Knotts, T.A., Wang, L.P., Li, G., Dobrowsky, R.T., Florant, G.L., Summers, S.A., 2003. A role for ceramide, but not diacylglycerol, in the antagonism of insulin signal transduction by saturated fatty acids. J. Biol. Chem. 278, 10297-10303. http://dx.doi.org/10.1074/jbc.M212307200.

Chiang, N., Arita, M., Serhan, C.N., 2005. Anti-inflammatory circuitry: lipoxin aspirin-triggered lipoxins and their receptor ALX. Prostagl. Leukot. Essent. Fat. Acids 73, 163-177. http://dx.doi.org/10.1016/j.plefa.2005.05.003.

Claria, J., Serhan, C.N., 1995. Aspirin triggers previously undescribed bioactive eicosanoids by human endothelial cell-leukocyte interactions. Proc. Natl. Acad. Sci. U. S. A. 92, 9475-9479.

Claria, J., Dalli, J., Yacoubian, S., Gao, F., Serhan, C.N., 2012. Resolvin D1 and resolvin D2 govern local inflammatory tone in obese fat. J. Immunol. 189, 2597-2605. http://dx.doi.org/10.4049/jimmunol.1201272.

Claria, J., Nguyen, B.T., Madenci, A.L., Ozaki, C.K., Serhan, C.N., 2013. Diversity of lipid mediators in human adipose tissue depots. Am. J. Physiol. Cell Physiol. 304 C1141-C1149. http://dx.doi.org/10.1152/ajpcell.00351.2012.

Cole, B.K., Lieb, D.C., Dobrian, A.D., Nadler, J.L., 2013. 12- and 15-lipoxygenases in adipose tissue inflammation. Prostagl. Other Lipid Mediat. 104-105, 84-92. http://dx.doi.org/10.1016/j.prostaglandins.2012.07.004.

Cote, M., Matias, I., Lemieux, I., Petrosino, S., Almeras, N., Despres, J.P., Di Marzo, V. 2007. Circulating endocannabinoid levels, abdominal adiposity and related cardiometabolic risk factors in obese men. Int. J. Obes. Lond. 31, 692-699. http://dx.doi.org/10.1038/sj.ijo.0803539.

Cui, T., Schopfer, F.J., Zhang, J., Chen, K., Ichikawa, T., Baker, P.R., Batthyany, C. Chacko, B.K., Feng, X., Patel, R.P., Agarwal, A., Freeman, B.A., Chen, Y.E., 2006. Nitrated fatty acids: endogenous anti-inflammatory signaling mediators. J. Biol. Chem. 281, 35686-35698. http://dx.doi.org/10.1074/jbc.M603357200.

Damsgaard, C.T., Stark, K.D., Hjorth, M.F., Biltoft-Jensen, A., Astrup, A., Michaelsen, K.F., Lauritzen, L., 2013. n-3 PUFA status in school children is associated with beneficial lipid profile, reduced physical activity and increased blood pressure in boys. Br. J. Nutr. 110, 1304-1312. http://dx.doi.org/10.1017/ S0007114513000585.

Daniel, J., Maamar, H., Deb, C., Sirakova, T.D., Kolattukudy, P.E., 2011. Mycobacterium tuberculosis uses host triacylglycerol to accumulate lipid droplets and acquires a dormancy-like phenotype in lipid-loaded macrophages. PLoS Pathog. 7, e1002093. http://dx.doi.org/10.1371/journal.ppat.1002093.

de Luca, C., Olefsky, J.M., 2008. Inflammation and insulin resistance. FEBS Lett. 582 97-105. http://dx.doi.org/10.1016/j.febslet.2007.11.057.

DeFronzo, R.A., Tripathy, D., 2009. Skeletal muscle insulin resistance is the primary defect in type 2 diabetes. Diabetes Care 32 (Suppl. 2), S157-S163. http:/ dx.doi.org/10.2337/dc09-S302.

Dejana, E., Breviario, F., Caveda, L., 1994. Leukocyte-endothelial cell adhesive receptors. Clin. Exp. Rheumatol. 12 (Suppl. 10), S25-S28.

Di Marzo, V., 2008. The endocannabinoid system in obesity and type 2 diabetes. Diabetologia 51, 1356-1367. http://dx.doi.org/10.1007/s00125-008-1048-2.

Dichlberger, A., Kovanen, P.T., Schneider, W.J., 2013. Mast cells: from lipid droplets to lipid mediators. Clin. Sci. 125, 121-130. http://dx.doi.org/10.1042 CS20120602.

Ding, Q., Mracek, T., Gonzalez-Muniesa, P., Kos, K., Wilding, J., Trayhurn, P., Bing, C., 2009. Identification of macrophage inhibitory cytokine- 1 in adipose tissue and its secretion as an adipokine by human adipocytes. Endocrinology 150, 1688-1696. http://dx.doi.org/10.1210/en.2008-0952.

Dixon, R.A., Diehl, R.E., Opas, E., Rands, E., Vickers, P.J., Evans, J.F., Gillard, J.W., Miller, D.K., 1990. Requirement of a 5-lipoxygenase-activating protein for leukotriene synthesis. Nature 343, 282-284. http://dx.doi.org/10.1038 $343282 \mathrm{a} 0$.

Ebbert, J.O., Jensen, M.D., 2013. Fat depots, free fatty acids, and dyslipidemia. 
Nutrients 5, 498-508. http://dx.doi.org/10.3390/nu5020498.

Ekyalongo, R.C., Nakayama, H., Kina, K., Kaga, N., Iwabuchi, K., 2015. Organization and functions of glycolipid-enriched microdomains in phagocytes. Biochim. Biophys. Acta 1851, 90-97. http://dx.doi.org/10.1016/j.bbalip.2014.06.009.

Fang, X., Sweeney, G., 2006. Mechanisms regulating energy metabolism by adiponectin in obesity and diabetes. Biochem. Soc. Trans. 34, 798-801. http:/ dx.doi.org/10.1042/BST0340798.

Feldon, S.E., O'Loughlin, C.W., Ray, D.M., Landskroner-Eiger, S., Seweryniak, K.E. Phipps, R.P., 2006. Activated human T lymphocytes express cyclooxygenase-2 and produce proadipogenic prostaglandins that drive human orbital fibroblast differentiation to adipocytes. Am. J. Pathol. 169, 1183-1193. http:// dx.doi.org/10.2353/ajpath.2006.060434.

Fezza, F., Gasperi, V., Mazzei, C., Maccarrone, M., 2005. Radiochromatographic assay of N-acyl-phosphatidylethanolamine-specific phospholipase D activity. Anal. Biochem. 339, 113-120. http://dx.doi.org/10.1016/j.ab.2004.12.005.

Field, C.J., Angel, A., Clandinin, M.T., 1985. Relationship of diet to the fatty acid composition of human adipose tissue structural and stored lipids. Am. J. Clin. Nutr. 42, 1206-1220.

Finck, B.N., Hall, A.M., 2015. Does diacylglycerol accumulation in fatty liver disease cause hepatic insulin resistance? Biomed. Res. Int. 2015, 104132. http:/ dx.doi.org/10.1155/2015/104132.

Flickinger, B.D., Matsuo, N., 2003. Nutritional characteristics of DAG oil. Lipids 38, $129-132$

Forman, B.M., Tontonoz, P., Chen, J., Brun, R.P., Spiegelman, B.M., Evans, R.M., 1995 15 -Deoxy-delta 12,14 -prostaglandin $\mathrm{J} 2$ is a ligand for the adipocyte determination factor PPAR gamma. Cell 83, 803-812.

Fredrikson, G., Stralfors, P., Nilsson, N.O., Belfrage, P., 1981. Hormone-sensitive lipase of rat adipose tissue. Purification and some properties. J. Biol. Chem. 256, 6311-6320.

Fujimoto, T., Parton, R.G., 2011. Not just fat: the structure and function of the lipid droplet. Cold Spring Harb. Perspect. Biol. 3 http://dx.doi.org/10.1101/ cshperspect.a004838.

Gandotra, S., Le Dour, C., Bottomley, W., Cervera, P., Giral, P., Reznik, Y., Charpentier, G., Auclair, M., Delepine, M., Barroso, I., Semple, R.K., Lathrop, M. Lascols, O., Capeau, J., O'Rahilly, S., Magre, J., Savage, D.B., Vigouroux, C., 2011. Perilipin deficiency and autosomal dominant partial lipodystrophy. N. Engl. J. Med. 364, 740-748. http://dx.doi.org/10.1056/NEJMoa1007487.

Garcia-Alonso, V., Lopez-Vicario, C., Titos, E., Moran-Salvador, E., Gonzalez-Periz, A., Rius, B., Parrizas, M., Werz, O., Arroyo, V., Claria, J., 2013. Coordinate functional regulation between microsomal prostaglandin E synthase-1 (mPGES-1) and peroxisome proliferator-activated receptor gamma (PPARgamma) in the conversion of white-to-brown adipocytes. J. Biol. Chem. 288, 28230-28242. http:// dx.doi.org/10.1074/jbc.M113.468603.

Goncalves, P., Martel, F., 2013. Butyrate and colorectal cancer: the role of butyrate transport. Curr. Drug Metab. 14, 994-1008.

Gong, J., Sun, Z., Wu, L., Xu, W., Schieber, N., Xu, D., Shui, G., Yang, H., Parton, R.G. Li, P., 2011. Fsp27 promotes lipid droplet growth by lipid exchange and transfer at lipid droplet contact sites. J. Cell Biol. 195, 953-963. http://dx.doi.org $10.1083 /$ jcb.201104142.

Gonzalez-Periz, A., Planaguma, A., Gronert, K., Miquel, R., Lopez-Parra, M., Titos, E., Horrillo, R., Ferre, N., Deulofeu, R., Arroyo, V., Rodes, J., Claria, J., 2006. Docosahexaenoic acid (DHA) blunts liver injury by conversion to protective lipid mediators: protectin D1 and 17S-hydroxy-DHA. FASEB J. 20, 2537-2539. http:// dx.doi.org/10.1096/fj.06-6250fje.

Gonzalez-Periz, A., Horrillo, R., Ferre, N., Gronert, K., Dong, B., Moran-Salvador, E Titos, E., Martinez-Clemente, M., Lopez-Parra, M., Arroyo, V., Claria, J., 2009 Obesity-induced insulin resistance and hepatic steatosis are alleviated by omega-3 fatty acids: a role for resolvins and protectins. FASEB J. 23, 1946-1957. http://dx.doi.org/10.1096/fj.08-125674.

Grahn, T.H., Kaur, R., Yin, J., Schweiger, M., Sharma, V.M., Lee, M.J., Ido, Y., Smas, C.M., Zechner, R., Lass, A., Puri, V., 2014. Fat-specific protein 27 (FSP27) interacts with adipose triglyceride lipase (ATGL) to regulate lipolysis and insulin sensitivity in human adipocytes. J. Biol. Chem. 289, 12029-12039. http://dx.doi.org/10.1074/ jbc.M113.539890.

Granneman, J.G., Moore, H.P., Granneman, R.L., Greenberg, A.S., Obin, M.S., Zhu, Z 2007. Analysis of lipolytic protein trafficking and interactions in adipocytes. J. Biol. Chem. 282, 5726-5735. http://dx.doi.org/10.1074/jbc.M610580200.

Greenberg, A.S., Coleman, R.A., Kraemer, F.B., McManaman, J.L., Obin, M.S., Puri, V., Yan, Q.W. Miyoshi, H., Mashek, D.G., 2011. The role of lipid droplets in metabolic disease in rodents and humans. J. Clin. Invest. 121, 2102-2110. http:// dx.doi.org/10.1172/JCI46069.

Gresset, A., Sondek, J., Harden, T.K., 2012. The phospholipase C isozymes and their regulation. Sub Cell. Biochem. 58, 61-94. http://dx.doi.org/10.1007/978-94007-3012-0_3.

Gross, D.N., Miyoshi, H., Hosaka, T., Zhang, H.H., Pino, E.C., Souza, S., Obin, M. Greenberg, A.S., Pilch, P.F., 2006. Dynamics of lipid droplet-associated proteins during hormonally stimulated lipolysis in engineered adipocytes: stabilization and lipid droplet binding of adipocyte differentiation-related protein/adipophilin. Mol. Endocrinol. 20, 459-466. http://dx.doi.org/10.1210/ me.2005-0323.

Haemmerle, G., Zimmermann, R., Hayn, M., Theussl, C., Waeg, G., Wagner, E. Sattler, W., Magin, T.M., Wagner, E.F., Zechner, R., 2002. Hormone-sensitive lipase deficiency in mice causes diglyceride accumulation in adipose tissue, muscle, and testis. J. Biol. Chem. 277, 4806-4815. http://dx.doi.org/10.1074/ jbc.M110355200.
Hajduch, E., Balendran, A., Batty, I.H., Litherland, G.J., Blair, A.S., Downes, C.P., Hundal, H.S., 2001. Ceramide impairs the insulin-dependent membrane recruitment of protein kinase B leading to a loss in downstream signalling in L6 skeletal muscle cells. Diabetologia 44, 173-183. http://dx.doi.org/10.1007/ s001250051596.

Hannun, Y.A., Obeid, L.M., 2008. Principles of bioactive lipid signalling: lessons from sphingolipids. Nat. Rev. Mol. Cell Biol. 9, 139-150. http://dx.doi.org/10.1038/ nrm2329.

Harvey Lodish, A.B., Zipursky, S Lawrence, Matsudaira, Paul, Baltimore, David, Darnell, James, 2000. Section 3.4 membrane proteins. In: Freeman, W.H. (Ed.), Molecular Cell Biology, fourth ed. Mc Millan, New York.

Haus, J.M., Kashyap, S.R., Kasumov, T., Zhang, R., Kelly, K.R., Defronzo, R.A., Kirwan, J.P., 2009. Plasma ceramides are elevated in obese subjects with type 2 diabetes and correlate with the severity of insulin resistance. Diabetes 58, 337-343. http://dx.doi.org/10.2337/db08-1228.

Hellmann, J., Tang, Y., Kosuri, M., Bhatnagar, A., Spite, M., 2011. Resolvin D1 decreases adipose tissue macrophage accumulation and improves insulin sensitivity in obese-diabetic mice. FASEB J. 25, 2399-2407. http://dx.doi.org/10.1096/ fj.10-178657.

Hla, T., Dannenberg, A.J., 2012. Sphingolipid signaling in metabolic disorders. Cell Metab. 16, 420-434. http://dx.doi.org/10.1016/j.cmet.2012.06.017.

Holland, W.L., Brozinick, J.T., Wang, L.P., Hawkins, E.D., Sargent, K.M., Liu, Y., Narra, K., Hoehn, K.L., Knotts, T.A., Siesky, A., Nelson, D.H., Karathanasis, S.K., Fontenot, G.K., Birnbaum, M.J., Summers, S.A., 2007. Inhibition of ceramide synthesis ameliorates glucocorticoid-, saturated-fat-, and obesity-induced insulin resistance. Cell Metab. 5, 167-179. http://dx.doi.org/10.1016/ j.cmet.2007.01.002.

Holland, W.L., Miller, R.A., Wang, Z.V., Sun, K., Barth, B.M., Bui, H.H., Davis, K.E., Bikman, B.T., Halberg, N., Rutkowski, J.M., Wade, M.R., Tenorio, V.M., Kuo, M.S., Brozinick, J.T., Zhang, B.B., Birnbaum, M.J., Summers, S.A., Scherer, P.E., 2011. Receptor-mediated activation of ceramidase activity initiates the pleiotropic actions of adiponectin. Nat. Med. 17, 55-63. http://dx.doi.org/10.1038/nm.2277.

Holm, C., Kirchgessner, T.G., Svenson, K.L., Fredrikson, G., Nilsson, S., Miller, C.G., Shively, J.E., Heinzmann, C., Sparkes, R.S., Mohandas, T., et al., 1988. Hormonesensitive lipase: sequence, expression, and chromosomal localization to 19 cent-q13.3. Science 241, 1503-1506.

Horrillo, R., Gonzalez-Periz, A., Martinez-Clemente, M., Lopez-Parra, M., Ferre, N., Titos, E., Moran-Salvador, E., Deulofeu, R., Arroyo, V., Claria, J., 2010. 5lipoxygenase activating protein signals adipose tissue inflammation and lipid dysfunction in experimental obesity. J. Immunol. 184, 3978-3987. http:// dx.doi.org/10.4049/jimmunol.0901355.

Hossain, M.S., Chowdhury, A.A., Rahman, M.S., Nishimura, K., Jisaka, M., Nagaya, T., Shono, F., Yokota, K., 2012. Stable expression of lipocalin-type prostaglandin D synthase in cultured preadipocytes impairs adipogenesis program independently of endogenous prostanoids. Exp. Cell Res. 318, 408-415. http:// dx.doi.org/10.1016/j.yexcr.2011.11.003.

Hotamisligil, G.S., 2006. Inflammation and metabolic disorders. Nature 444, 860-867. http://dx.doi.org/10.1038/nature05485.

Hu, J., Zhang, Z., Shen, W.J., Azhar, S., 2010. Cellular cholesterol delivery, intracellular processing and utilization for biosynthesis of steroid hormones. Nutr. Metab. Lond. 7, 47. http://dx.doi.org/10.1186/1743-7075-7-47.

Hudert, C.A., Weylandt, K.H., Lu, Y., Wang, J., Hong, S., Dignass, A., Serhan, C.N., Kang, J.X., 2006. Transgenic mice rich in endogenous omega-3 fatty acids are protected from colitis. Proc. Natl. Acad. Sci. U. S. A. 103, 11276-11281. http:// dx.doi.org/10.1073/pnas.0601280103.

Izzo, A.A., Piscitelli, F., Capasso, R., Aviello, G., Romano, B., Borrelli, F., Petrosino, S., Di Marzo, V., 2009. Peripheral endocannabinoid dysregulation in obesity: relation to intestinal motility and energy processing induced by food deprivation and re-feeding. Br. J. Pharmacol. 158, 451-461. http://dx.doi.org/10.1111/j.14765381.2009.00183.x.

Jenkins, C.M., Mancuso, D.J., Yan, W., Sims, H.F., Gibson, B., Gross, R.W., 2004. Identification, cloning, expression, and purification of three novel human calcium-independent phospholipase A2 family members possessing triacylglycerol lipase and acylglycerol transacylase activities. J. Biol. Chem. 279, 48968-48975. http://dx.doi.org/10.1074/jbc.M407841200.

Kansanen, E., Jyrkkanen, H.K., Volger, O.L., Leinonen, H., Kivela, A.M., Hakkinen, S.K. Woodcock, S.R., Schopfer, F.J., Horrevoets, A.J., Yla-Herttuala, S., Freeman, B.A., Levonen, A.L., 2009. Nrf2-dependent and -independent responses to nitro-fatty acids in human endothelial cells: identification of heat shock response as the major pathway activated by nitro-oleic acid. J. Biol. Chem. 284, 33233-33241. http://dx.doi.org/10.1074/jbc.M109.064873.

Kather, H., Bieger, W., Michel, G., Aktories, K., Jakobs, K.H., 1985. Human fat cell lipolysis is primarily regulated by inhibitory modulators acting through distinct mechanisms. J. Clin. Invest. 76, 1559-1565. http://dx.doi.org/10.1172/JCI112137.

Keller, P., Petrie, J.T., De Rose, P., Gerin, I., Wright, W.S., Chiang, S.H., Nielsen, A.R., Fischer, C.P., Pedersen, B.K., MacDougald, O.A., 2008. Fat-specific protein 27 regulates storage of triacylglycerol. J. Biol. Chem. 283, 14355-14365. http:// dx.doi.org/10.1074/jbc.M708323200.

Kelley, E.E., Batthyany, C.I., Hundley, N.J., Woodcock, S.R., Bonacci, G., Del Rio, J.M., Schopfer, F.J., Lancaster Jr., J.R., Freeman, B.A., Tarpey, M.M., 2008. Nitro-oleic acid, a novel and irreversible inhibitor of xanthine oxidoreductase. J. Biol. Chem. 283, 36176-36184. http://dx.doi.org/10.1074/jbc.M802402200.

Kelley, E.E., Baust, J., Bonacci, G., Golin-Bisello, F., Devlin, J.E., St Croix, C.M., Watkins, S.C., Gor, S., Cantu-Medellin, N., Weidert, E.R., Frisbee, J.C., Gladwin, M.T., Champion, H.C., Freeman, B.A., Khoo, N.K., 2014. Fatty acid 
nitroalkenes ameliorate glucose intolerance and pulmonary hypertension in high-fat diet-induced obesity. Cardiovasc. Res. 101, 352-363. http://dx.doi.org/ $10.1093 / \mathrm{cvr} / \mathrm{cvt} 341$.

Khoo, N.K., Freeman, B.A., 2010. Electrophilic nitro-fatty acids: anti-inflammatory mediators in the vascular compartment. Curr. Opin. Pharmacol. 10, 179-184. http://dx.doi.org/10.1016/j.coph.2009.11.003.

Kim, H.J., Lee, K.T., Lee, M.K., Jeon, S.M., Choi, M.S., 2006. Diacylglycerol-enriched structured lipids containing CLA and capric acid alter body fat mass and lipid metabolism in rats. Ann. Nutr. Metab. 50, 219-228. http://dx.doi.org/10.1159/ 000090765.

Kim, J.Y., Liu, K., Zhou, S., Tillison, K., Wu, Y., Smas, C.M., 2008. Assessment of fatspecific protein 27 in the adipocyte lineage suggests a dual role for FSP27 in adipocyte metabolism and cell death. Am. J. Physiol. Endocrinol. Metab. 294, E654-E667. http://dx.doi.org/10.1152/ajpendo.00104.2007.

Kim, C.A., Delepine, M., Boutet, E., El Mourabit, H., Le Lay, S., Meier, M., Nemani, M., Bridel, E., Leite, C.C., Bertola, D.R., Semple, R.K., O'Rahilly, S., Dugail, I., Capeau, J., Lathrop, M., Magre, J., 2008. Association of a homozygous nonsense caveolin-1 mutation with Berardinelli-Seip congenital lipodystrophy. J. Clin. Endocrinol. Metab. 93, 1129-1134. http://dx.doi.org/10.1210/jc.2007-1328.

Kimura, S., Tsuchiya, H., Inage, H., Meguro, S., Matsuo, N., Tokimitsu, I., 2006. Effects of dietary diacylglycerol on the energy metabolism. Int. J. Vitam. Nutr. Res. 76, 75-79. http://dx.doi.org/10.1024/0300-9831.76.2.75.

Kolak, M., Westerbacka, J., Velagapudi, V.R., Wagsater, D., Yetukuri, L., Makkonen, J., Rissanen, A., Hakkinen, A.M., Lindell, M., Bergholm, R., Hamsten, A., Eriksson, P., Fisher, R.M., Oresic, M., Yki-Jarvinen, H., 2007. Adipose tissue inflammation and increased ceramide content characterize subjects with high liver fat content independent of obesity. Diabetes 56, 1960-1968. http://dx.doi.org/10.2337/ db07-0111.

Kolter, T., Doering, T., Wilkening, G., Werth, N., Sandhoff, K., 1999. Recent advances in the biochemistry of glycosphingolipid metabolism. Biochem. Soc. Trans. 27, 409-415.

Kovsan, J., Ben-Romano, R., Souza, S.C., Greenberg, A.S., Rudich, A., 2007. Regulation of adipocyte lipolysis by degradation of the perilipin protein: nelfinavir enhances lysosome-mediated perilipin proteolysis. J. Biol. Chem. 282, 21704-21711. http://dx.doi.org/10.1074/jbc.M702223200.

Krahmer, N., Farese Jr., R.V., Walther, T.C., 2013. Balancing the fat: lipid droplets and human disease. EMBO Mol. Med. 5, 905-915. http://dx.doi.org/10.1002/ emmm.201100671.

Kuhn, H., Banthiya, S., van Leyen, K., 2015. Mammalian lipoxygenases and their biological relevance. Biochim. Biophys. Acta 1851, 308-330. http://dx.doi.org/ 10.1016/j.bbalip.2014.10.002.

Kujubu, D.A., Fletcher, B.S., Varnum, B.C., Lim, R.W., Herschman, H.R., 1991. TIS10, a phorbol ester tumor promoter-inducible mRNA from Swiss 3T3 cells, encodes a novel prostaglandin synthase/cyclooxygenase homologue. J. Biol. Chem. 266, 12866-12872.

Lafontan, M., Barbe, P., Galitzky, J., Tavernier, G., Langin, D., Carpene, C., BousquetMelou, A., Berlan, M., 1997. Adrenergic regulation of adipocyte metabolism. Hum. Reprod. 12 (Suppl. 1), 6-20.

Larsen, P.J., Tennagels, N., 2014. On ceramides, other sphingolipids and impaired glucose homeostasis. Mol. Metab. 3, 252-260. http://dx.doi.org/10.1016/ j.molmet.2014.01.011.

Lass, A., Zimmermann, R., Haemmerle, G., Riederer, M., Schoiswohl, G., Schweiger, M., Kienesberger, P., Strauss, J.G., Gorkiewicz, G., Zechner, R., 2006. Adipose triglyceride lipase-mediated lipolysis of cellular fat stores is activated by CGI-58 and defective in Chanarin-Dorfman Syndrome. Cell Metab. 3, 309-319. http://dx.doi.org/10.1016/j.cmet.2006.03.005.

Li, Y., Zhang, J., Schopfer, F.J., Martynowski, D., Garcia-Barrio, M.T., Kovach, A., SuinoPowell, K., Baker, P.R., Freeman, B.A., Chen, Y.E., Xu, H.E., 2008. Molecular recognition of nitrated fatty acids by PPAR gamma. Nat. Struct. Mol. Biol. 15, 865-867. http://dx.doi.org/10.1038/nsmb.1447.

Li, L.O., Klett, E.L., Coleman, R.A., 2010. Acyl-CoA synthesis, lipid metabolism and lipotoxicity. Biochim. Biophys. Acta 1801, 246-251. http://dx.doi.org/10.1016/ j.bbalip.2009.09.024.

Li, P., Oh da, Y., Bandyopadhyay, G., Lagakos, W.S., Talukdar, S., Osborn, O., Johnson, A., Chung, H., Mayoral, R., Maris, M., Ofrecio, J.M., Taguchi, S., Lu, M. Olefsky, J.M., 2015. LTB4 promotes insulin resistance in obese mice by acting on macrophages, hepatocytes and myocytes. Nat. Med. 21, 239-247. http:// dx.doi.org/10.1038/nm.3800.

Liu, P., Leffler, B.J., Weeks, L.K., Chen, G., Bouchard, C.M., Strawbridge, A.B., Elmendorf, J.S., 2004. Sphingomyelinase activates GLUT4 translocation via a cholesterol-dependent mechanism. Am. J. Physiol. Cell Physiol. 286, C317-C329. http://dx.doi.org/10.1152/ajpcell.00073.2003.

Liu, Y., Retnakaran, R., Hanley, A., Tungtrongchitr, R., Shaw, C., Sweeney, G., 2007. Total and high molecular weight but not trimeric or hexameric forms of adiponectin correlate with markers of the metabolic syndrome and liver injury in Thai subjects. J. Clin. Endocrinol. Metab. 92, 4313-4318. http://dx.doi.org/ 10.1210/jc.2007-0890.

Liu, K., Zhou, S., Kim, J.Y., Tillison, K., Majors, D., Rearick, D., Lee, J.H., FernandezBoyanapalli, R.F., Barricklow, K., Houston, M.S., Smas, C.M., 2009. Functional analysis of FSP27 protein regions for lipid droplet localization, caspasedependent apoptosis, and dimerization with CIDEA. Am. J. Physiol. Endocrinol. Metab. 297, E1395-E1413. http://dx.doi.org/10.1152/ ajpendo.00188.2009.

Liu, Y., Xue, C., Zhang, Y., Xu, Q., Yu, X., Zhang, X., Wang, J., Zhang, R., Gong, X., Guo, C., 2011. Triglyceride with medium-chain fatty acids increases the activity and expression of hormone-sensitive lipase in white adipose tissue of C57BL/6 mice. Biosci. Biotechnol. Biochem. 75, 1939-1944. http://dx.doi.org/10.1271/ bbb.110321.

Lopez-Vicario, C., Gonzalez-Periz, A., Rius, B., Moran-Salvador, E., Garcia-Alonso, V., Lozano, J.J., Bataller, R., Cofan, M., Kang, J.X., Arroyo, V., Claria, J., Titos, E., 2014 Molecular interplay between Delta5/Delta6 desaturases and long-chain fatty acids in the pathogenesis of non-alcoholic steatohepatitis. Gut 63, 344-355. http://dx.doi.org/10.1136/gutjnl-2012-303179.

Lopez-Vicario, C., Rius, B., Alcaraz-Quiles, J., Garcia-Alonso, V., Lopategi, A., Titos, E., Claria, J., 2015. Pro-resolving mediators produced from EPA and DHA: overview of the pathways involved and their mechanisms in metabolic syndrome and related liver diseases. Eur. J. Pharmacol. http://dx.doi.org/10.1016 j.ejphar.2015.03.092.

Lopez-Vicario, C., Alcaraz-Quiles, J., Garcia-Alonso, V., Rius, B., Hwang, S.H., Titos, E. Lopategi, A., Hammock, B.D., Arroyo, V., Claria, J., 2015. Inhibition of soluble epoxide hydrolase modulates inflammation and autophagy in obese adipose tissue and liver: role for omega-3 epoxides. Proc. Natl. Acad. Sci. U. S. A. 112, 536-541. http://dx.doi.org/10.1073/pnas.1422590112.

Luo, N., Liu, J., Chung, B.H., Yang, Q., Klein, R.L., Garvey, W.T., Fu, Y., 2010. Macrophage adiponectin expression improves insulin sensitivity and protects against inflammation and atherosclerosis. Diabetes 59, 791-799. http://dx.doi.org/ 10.2337/db09-1338.

Magre, J., Delepine, M., Khallouf, E., Gedde-Dahl Jr., T., Van Maldergem, L., Sobel, E., Papp, J., Meier, M., Megarbane, A., Bachy, A., Verloes, A., d'Abronzo, F.H. Seemanova, E., Assan, R., Baudic, N., Bourut, C., Czernichow, P., Huet, F. Grigorescu, F., de Kerdanet, M., Lacombe, D., Labrune, P., Lanza, M., Loret, H. Matsuda, F., Navarro, J. Nivelon-Chevalier, A., Polak, M., Robert, J.J., Tric, P. Tubiana-Rufi, N., Vigouroux, C., Weissenbach, J., Savasta, S., Maassen, J.A., Trygstad, O., Bogalho, P., Freitas, P., Medina, J.L., Bonnicci, F., Joffe, B.I., Loyson, G., Panz, V.R., Raal, F.J., O'Rahilly, S., Stephenson, T., Kahn, C.R., Lathrop, M. Capeau, J., Group, B.W., 2001. Identification of the gene altered in BerardinelliSeip congenital lipodystrophy on chromosome 11q13. Nat. Genet. 28, 365-370. http://dx.doi.org/10.1038/ng585.

Martin, S., Parton, R.G., 2006. Lipid droplets: a unified view of a dynamic organelle. Nat. Rev. Mol. Cell Biol. 7, 373-378. http://dx.doi.org/10.1038/nrm1912.

Martinez-Botas, J., Anderson, J.B., Tessier, D., Lapillonne, A., Chang, B.H., Quast, M.J. Gorenstein, D., Chen, K.H., Chan, L., 2000. Absence of perilipin results in leanness and reverses obesity in $\operatorname{Lepr}(\mathrm{db} / \mathrm{db})$ mice. Nat. Genet. 26, 474-479. http:// dx.doi.org/10.1038/82630.

Masuda, Y., Itabe, H., Odaki, M., Hama, K., Fujimoto, Y., Mori, M., Sasabe, N., Aoki, J., Arai, H., Takano, T., 2006. ADRP/adipophilin is degraded through the proteasome-dependent pathway during regression of lipid-storing cells. J. Lipid Res. 47, 87-98. http://dx.doi.org/10.1194/jlr.M500170-JLR200.

Matsuzawa, Y., 2010. Adiponectin: a key player in obesity related disorders. Curr Pharm. Des. 16, 1896-1901.

Melo, R.C., D'Avila, H., Fabrino, D.L., Almeida, P.E., Bozza, P.T., 2003. Macrophage lipid body induction by Chagas disease in vivo: putative intracellular domains for eicosanoid formation during infection. Tissue Cell 35, 59-67.

Meng, X., Zou, D., Shi, Z., Duan, Z., Mao, Z., 2004. Dietary diacylglycerol prevents high-fat diet-induced lipid accumulation in rat liver and abdominal adipose tissue. Lipids 39, 37-41.

Murase, T., Mizuno, T., Omachi, T, Onizawa, K, Komine, Y, Kondo, H., Hase, T. Tokimitsu, I., 2001. Dietary diacylglycerol suppresses high fat and high sucrose diet-induced body fat accumulation in C57BL/6J mice. J. Lipid Res. 42, 372-378.

Murase, T., Nagasawa, A., Suzuki, J., Wakisaka, T., Hase, T., Tokimitsu, I., 2002. Dietary alpha-linolenic acid-rich diacylglycerols reduce body weight gain accompanying the stimulation of intestinal beta-oxidation and related gene expressions in C57BL/KsJ-db/db mice. J. Nutr. 132, 3018-3022.

Murase, T., Aoki, M., Tokimitsu, I., 2005. Supplementation with alpha-linolenic acidrich diacylglycerol suppresses fatty liver formation accompanied by an upregulation of beta-oxidation in Zucker fatty rats. Biochim. Biophys. Acta 1733 , 224-231. http://dx.doi.org/10.1016/j.bbalip.2004.12.015.

Murphy, D.J., 2001. The biogenesis and functions of lipid bodies in animals, plants and microorganisms. Prog. Lipid Res. 40, 325-438.

Nagao, T., Watanabe, H., Goto, N., Onizawa, K., Taguchi, H., Matsuo, N., Yasukawa, T., Tsushima, R., Shimasaki, H., Itakura, H., 2000. Dietary diacylglycerol suppresses accumulation of body fat compared to triacylglycerol in men in a double-blind controlled trial. J. Nutr. 130, 792-797.

Narala, V.R., Subramani, P.A., Narasimha, V.R., Shaik, F.B., Panati, K., 2014. The role of nitrated fatty acids and peroxisome proliferator-activated receptor gamma in modulating inflammation. Int. Immunopharmacol. 23, 283-287. http:// dx.doi.org/10.1016/j.intimp.2014.09.009.

Neuhofer, A., Zeyda, M., Mascher, D., Itariu, B.K., Murano, I., Leitner, L. Hochbrugger, E.E., Fraisl, P., Cinti, S., Serhan, C.N., Stulnig, T.M., 2013. Impaired local production of proresolving lipid mediators in obesity and 17-HDHA as a potential treatment for obesity-associated inflammation. Diabetes 62 1945-1956. http://dx.doi.org/10.2337/db12-0828.

Nishino, N., Tamori, Y., Tateya, S., Kawaguchi, T., Shibakusa, T., Mizunoya, W. Inoue, K., Kitazawa, R., Kitazawa, S., Matsuki, Y., Hiramatsu, R., Masubuchi, S. Omachi, A., Kimura, K., Saito, M., Amo, T., Ohta, S., Yamaguchi, T., Osumi, T. Cheng, J., Fujimoto, T., Nakao, H., Nakao, K., Aiba, A., Okamura, H., Fushiki, T., Kasuga, M., 2008. FSP27 contributes to efficient energy storage in murine white adipocytes by promoting the formation of unilocular lipid droplets. J. Clin. Invest. 118, 2808-2821. http://dx.doi.org/10.1172/JCI34090.

Nogueiras, R., Diaz-Arteaga, A., Lockie, S.H., Velasquez, D.A., Tschop, J., Lopez, M. 
Cadwell, C.C., Dieguez, C., Tschop, M.H., 2009. The endocannabinoid system: role in glucose and energy metabolism. Pharmacol. Res. Off. J. Ital. Pharmacol. Soc. 60, 93-98. http://dx.doi.org/10.1016/j.phrs.2009.04.004.

Nordstrom, E.A., Ryden, M., Backlund, E.C., Dahlman, I., Kaaman, M., Blomqvist, L. Cannon, B., Nedergaard, J., Arner, P., 2005. A human-specific role of cell deathinducing DFFA (DNA fragmentation factor-alpha)-like effector A (CIDEA) in adipocyte lipolysis and obesity. Diabetes 54, 1726-1734.

Olefsky, J.M., Glass, C.K., 2010. Macrophages, inflammation, and insulin resistance. Annu. Rev. Physiol. 72, 219-246. http://dx.doi.org/10.1146/annurev-physiol021909-135846.

Osuga, J., Ishibashi, S., Oka, T., Yagyu, H., Tozawa, R., Fujimoto, A., Shionoiri, F. Yahagi, N., Kraemer, F.B., Tsutsumi, O., Yamada, N., 2000. Targeted disruption of hormone-sensitive lipase results in male sterility and adipocyte hypertrophy, but not in obesity. Proc. Natl. Acad. Sci. U. S. A. 97, 787-792.

Ouchi, N., Parker, J.L., Lugus, J.J., Walsh, K., 2011. Adipokines in inflammation and metabolic disease. Nat. Rev. Immunol. 11, 85-97. http://dx.doi.org/10.1038/ nri2921.

Pagano, C., Pilon, C., Calcagno, A., Urbanet, R., Rossato, M., Milan, G., Bianchi, K. Rizzuto, R., Bernante, P., Federspil, G., Vettor, R., 2007. The endogenous cannabinoid system stimulates glucose uptake in human fat cells via phosphatidylinositol 3-kinase and calcium-dependent mechanisms. J. Clin. Endocrinol. Metab. 92, 4810-4819. http://dx.doi.org/10.1210/jc.2007-0768.

Panigrahy, D., Kalish, B.T., Huang, S., Bielenberg, D.R., Le, H.D., Yang, J., Edin, M.L. Lee, C.R., Benny, O., Mudge, D.K., Butterfield, C.E., Mammoto, A., Mammoto, T., Inceoglu, B., Jenkins, R.L., Simpson, M.A., Akino, T., Lih, F.B., Tomer, K.B. Ingber, D.E., Hammock, B.D., Falck, J.R., Manthati, V.L., Kaipainen, A D'Amore, P.A., Puder, M., Zeldin, D.C., Kieran, M.W., 2013. Epoxyeicosanoids promote organ and tissue regeneration. Proc. Natl. Acad. Sci. U. S. A. 110, 13528-13533. http://dx.doi.org/10.1073/pnas.1311565110.

Papamandjaris, A.A., MacDougall, D.E., Jones, P.J., 1998. Medium chain fatty acic metabolism and energy expenditure: obesity treatment implications. Life Sci. 62, 1203-1215.

Pardo, V., Gonzalez-Rodriguez, A., Guijas, C., Balsinde, J., Valverde, A.M., 2015. Opposite cross-Talk by Oleate and palmitate on insulin signaling in hepatocytes through macrophage activation. J. Biol. Chem. 290, 11663-11677. http:// dx.doi.org/10.1074/jbc.M115.649483.

Peyron, P., Vaubourgeix, J., Poquet, Y., Levillain, F., Botanch, C., Bardou, F., Daffe, M. Emile, J.F., Marchou, B., Cardona, P.J., de Chastellier, C., Altare, F., 2008. Foamy macrophages from tuberculous patients' granulomas constitute a nutrient-rich reservoir for M. tuberculosis persistence. PLoS Pathog. 4, e1000204, 10.1371/ journal.ppat.1000204.

Pittman, R.C., Khoo, J.C., Steinberg, D., 1975. Cholesterol esterase in rat adipose tissue and its activation by cyclic adenosine 3':5'-monophosphate-dependent protein kinase. J. Biol. Chem. 250, 4505-4511.

Planaguma, A., Titos, E., Lopez-Parra, M., Gaya, J., Pueyo, G., Arroyo, V., Claria, J., 2002. Aspirin (ASA) regulates 5-lipoxygenase activity and peroxisome proliferator-activated receptor alpha-mediated CINC-1 release in rat liver cells: novel actions of lipoxin A4 (LXA4) and ASA-triggered 15-epi-LXA4. FASEB J. 16 1937-1939. http://dx.doi.org/10.1096/fj.02-0224fje.

Powell, D.J., Hajduch, E., Kular, G., Hundal, H.S., 2003. Ceramide disables 3 phosphoinositide binding to the pleckstrin homology domain of protein kinase B (PKB)/Akt by a PKCzeta-dependent mechanism. Mol. Cell Biol. 23, 7794-7808.

Powell, D.J., Turban, S., Gray, A., Hajduch, E., Hundal, H.S., 2004. Intracellular ceramide synthesis and protein kinase Czeta activation play an essential role in palmitate-induced insulin resistance in rat L6 skeletal muscle cells. Biochem. J. 382, 619-629. http://dx.doi.org/10.1042/BJ20040139.

Puri, V., Konda, S., Ranjit, S., Aouadi, M., Chawla, A., Chouinard, M., Chakladar, A., Czech, M.P., 2007. Fat-specific protein 27, a novel lipid droplet protein that enhances triglyceride storage. J. Biol. Chem. 282, 34213-34218. http:// dx.doi.org/10.1074/jbc.M707404200.

Radmark, O., Shimizu, T. Jornvall, H., Samuelsson, B., 1984. Leukotriene A4 hydrolase in human leukocytes. Purification and properties. J. Biol. Chem. 259, 12339-12345.

Ranjit, S., Boutet, E., Gandhi, P., Prot, M., Tamori, Y., Chawla, A., Greenberg, A.S Puri, V., Czech, M.P., 2011. Regulation of fat specific protein 27 by isoprotereno and TNF-alpha to control lipolysis in murine adipocytes. J. Lipid Res. 52, 221-236. http://dx.doi.org/10.1194/jlr.M008771.

Redinger, R.N., 2009. Fat storage and the biology of energy expenditure. Transl. Res. 154, 52-60. http://dx.doi.org/10.1016/j.trsl.2009.05.003.

Rius, B., Titos, E., Moran-Salvador, E., Lopez-Vicario, C., Garcia-Alonso, V., GonzalezPeriz, A., Arroyo, V., Claria, J., 2014. Resolvin D1 primes the resolution process initiated by calorie restriction in obesity-induced steatohepatitis. FASEB J. 28 836-848. http://dx.doi.org/10.1096/fj.13-235614.

Robenek, M.J., Severs, N.J., Schlattmann, K., Plenz, G., Zimmer, K.P., Troyer, D. Robenek, H., 2004. Lipids partition caveolin-1 from ER membranes into lipid droplets: updating the model of lipid droplet biogenesis. FASEB J. 18, 866-868. http://dx.doi.org/10.1096/fj.03-0782fje.

Robenek, H., Robenek, M.J., Troyer, D., 2005. PAT family proteins pervade lipid droplet cores. J. Lipid Res. 46, 1331-1338. http://dx.doi.org/10.1194/ jlr.M400323-JLR200.

Romano, M., Claria, J., 2003. Cyclooxygenase-2 and 5-lipoxygenase converging functions on cell proliferation and tumor angiogenesis: implications for cancer therapy. FASEB J. 17, 1986-1995. http://dx.doi.org/10.1096/fj.03-0053rev.

Rouzer, C.A., Matsumoto, T., Samuelsson, B., 1986. Single protein from human leukocytes possesses 5-lipoxygenase and leukotriene A4 synthase activities. Proc. Natl. Acad. Sci. U. S. A. 83, 857-861.

Rubbo, H., 2013. Nitro-fatty acids: novel anti-inflammatory lipid mediators. Braz. J. Med. Biol. Res. 46, 728-734. http://dx.doi.org/10.1590/1414-431X20133202.

Rudolph, T.K., Freeman, B.A., 2009. Transduction of redox signaling by electrophileprotein reactions. Sci. Signal. 2, re7. http://dx.doi.org/10.1126/scisignal.290re7.

Samad, F., Hester, K.D., Yang, G., Hannun, Y.A., Bielawski, J., 2006. Altered adipose and plasma sphingolipid metabolism in obesity: a potential mechanism for cardiovascular and metabolic risk. Diabetes 55, 2579-2587. http://dx.doi.org/ $10.2337 / \mathrm{db06}-0330$.

Samsa, M.M., Mondotte, J.A., Iglesias, N.G., Assuncao-Miranda, I., Barbosa-Lima, G., Da Poian, A.T., Bozza, P.T., Gamarnik, A.V., 2009. Dengue virus capsid protein usurps lipid droplets for viral particle formation. PLoS Pathog. 5, e1000632, 10.1371/journal.ppat.1000632.

Samuelsson, B., Dahlen, S.E., Lindgren, J.A., Rouzer, C.A., Serhan, C.N., 1987. Leukotrienes and lipoxins: structures, biosynthesis, and biological effects. Science 237, 1171-1176.

Sanyal, A.J., 2005. Mechanisms of Disease: pathogenesis of nonalcoholic fatty liver disease. Nat. Clin. Pract. Gastroenterol. Hepatol. 2, 46-53. http://dx.doi.org/ 10.1038/ncpgasthep0084.

Sarzani, R., Bordicchia, M., Marcucci, P., Bedetta, S., Santini, S., Giovagnoli, A., Scappini, L., Minardi, D., Muzzonigro, G., Dessi-Fulgheri, P., Rappelli, A., 2009. Altered pattern of cannabinoid type 1 receptor expression in adipose tissue of dysmetabolic and overweight patients. Metabolism 58, 361-367. http:// dx.doi.org/10.1016/j.metabol.2008.10.009.

Schilling, J.D., Machkovech, H.M., He, L., Sidhu, R., Fujiwara, H., Weber, K., Ory, D.S., Schaffer, J.E., 2013. Palmitate and lipopolysaccharide trigger synergistic ceramide production in primary macrophages. J. Biol. Chem. 288, 2923-2932. http://dx.doi.org/10.1074/jbc.M112.419978.

Schmitz, G., Ecker, J., 2008. The opposing effects of n-3 and n-6 fatty acids. Prog. Lipid Res. 47, 147-155. http://dx.doi.org/10.1016/j.plipres.2007.12.004.

Schopfer, F.J., Lin, Y., Baker, P.R., Cui, T., Garcia-Barrio, M., Zhang, J., Chen, K., Chen, Y.E., Freeman, B.A., 2005. Nitrolinoleic acid: an endogenous peroxisome proliferator-activated receptor gamma ligand. Proc. Natl. Acad. Sci. U. S. A. 102 , 2340-2345. http://dx.doi.org/10.1073/pnas.0408384102.

Schopfer, F.J., Cole, M.P., Groeger, A.L., Chen, C.S., Khoo, N.K., Woodcock, S.R., GolinBisello, F., Motanya, U.N., Li, Y., Zhang, J., Garcia-Barrio, M.T., Rudolph, T.K., Rudolph, V., Bonacci, G., Baker, P.R., Xu, H.E., Batthyany, C.I., Chen, Y.E., Hallis, T.M., Freeman, B.A., 2010. Covalent peroxisome proliferator-activated receptor gamma adduction by nitro-fatty acids: selective ligand activity and anti-diabetic signaling actions. J. Biol. Chem. 285, 12321-12333. http:// dx.doi.org/10.1074/jbc.M109.091512.

Schopfer, F.J., Cipollina, C., Freeman, B.A., 2011. Formation and signaling actions of electrophilic lipids. Chem. Rev. 111, 5997-6021. http://dx.doi.org/10.1021/ cr200131e.

Schror, K., 1990. Platelet reactivity and arachidonic acid metabolism in type II hyperlipoproteinaemia and its modification by cholesterol-lowering agents. Eicosanoids 3, 67-73.

Schwab, J.M., Chiang, N., Arita, M., Serhan, C.N., 2007. Resolvin E1 and protectin D1 activate inflammation-resolution programmes. Nature 447, 869-874. http:// dx.doi.org/10.1038/nature05877.

Serhan, C.N., 2014. Pro-resolving lipid mediators are leads for resolution physiology. Nature 510, 92-101. http://dx.doi.org/10.1038/nature13479.

Serhan, C.N., Chiang, N., 2013. Resolution phase lipid mediators of inflammation: agonists of resolution. Curr. Opin. Pharmacol. 13, 632-640. http://dx.doi.org/ 10.1016/j.coph.2013.05.012.

Serhan, C.N., Sheppard, K.A., 1990. Lipoxin formation during human neutrophilplatelet interactions. Evidence for the transformation of leukotriene A4 by platelet 12-lipoxygenase in vitro. J. Clin. Invest. 85, 772-780. http://dx.doi.org/ 10.1172/JCI114503.

Serhan, C.N., Clish, C.B., Brannon, J., Colgan, S.P., Chiang, N., Gronert, K., 2000. Novel functional sets of lipid-derived mediators with antiinflammatory actions generated from omega-3 fatty acids via cyclooxygenase 2-nonsteroidal antiinflammatory drugs and transcellular processing. J. Exp. Med. 192, 1197-1204.

Serhan, C.N., Gotlinger, K., Hong, S., Lu, Y., Siegelman, J., Baer, T., Yang, R., Colgan, S.P., Petasis, N.A., 2006. Anti-inflammatory actions of neuroprotectin D1/protectin D1 and its natural stereoisomers: assignments of dihydroxy-containing docosatrienes. J. Immunol. 176, 1848-1859.

Serhan, C.N., Yang, R., Martinod, K., Kasuga, K., Pillai, P.S., Porter, T.F., Oh, S.F. Spite, M., 2009. Maresins: novel macrophage mediators with potent antiinflammatory and proresolving actions. J. Exp. Med. 206, 15-23. http://dx.doi.org/ 10.1084 /jem.20081880.

Shaw, J.E., Ramwell, P.W., 1968. Release of prostaglandin from rat epididymal fat pad on nervous and hormonal stimulation. J. Biol. Chem. 243, 1498-1503.

Shoelson, S.E., Lee, J., Goldfine, A.B., 2006. Inflammation and insulin resistance. J. Clin. Invest. 116, 1793-1801. http://dx.doi.org/10.1172/JCI29069.

Silvestri, C., Di Marzo, V., 2013. The endocannabinoid system in energy homeostasis and the etiopathology of metabolic disorders. Cell Metab. 17, 475-490. http:// dx.doi.org/10.1016/j.cmet.2013.03.001.

Simopoulos, A.P., 1999. Essential fatty acids in health and chronic disease. Am. J. Clin. Nutr. 70, 560S-569S.

Singh, R., Xiang, Y., Wang, Y., Baikati, K., Cuervo, A.M., Luu, Y.K., Tang, Y., Pessin, J.E., Schwartz, G.J., Czaja, M.J., 2009. Autophagy regulates adipose mass and differentiation in mice. J. Clin. Invest. 119, 3329-3339. http://dx.doi.org/10.1172/ JCI39228. 
Singh, M., Kaur, R., Lee, M.J., Pickering, R.T., Sharma, V.M., Puri, V., Kandror, K.V., 2014. Fat-specific protein 27 inhibits lipolysis by facilitating the inhibitory effect of transcription factor Egr1 on transcription of adipose triglyceride lipase. J. Biol. Chem. 289, 14481-14487. http://dx.doi.org/10.1074/jbc.C114.563080.

Sinha, D., Addya, S., Murer, E., Boden, G., 1999. 15-Deoxy-delta(12,14) prostaglandin J2: a putative endogenous promoter of adipogenesis suppresses the ob gene. Metabolism 48, 786-791.

Skinner, J.R., Shew, T.M., Schwartz, D.M., Tzekov, A., Lepus, C.M., Abumrad, N.A., Wolins, N.E., 2009. Diacylglycerol enrichment of endoplasmic reticulum or lipid droplets recruits perilipin 3/TIP47 during lipid storage and mobilization. J. Biol. Chem. 284, 30941-30948. http://dx.doi.org/10.1074/jbc.M109.013995.

Spector, A.A., Norris, A.W., 2007. Action of epoxyeicosatrienoic acids on cellular function. Am. J. Physiol. Cell Physiol. 292, C996-C1012. http://dx.doi.org/ 10.1152/ajpcell.00402.2006.

Spite, M., Hellmann, J., Tang, Y., Mathis, S.P., Kosuri, M., Bhatnagar, A., Jala, V.R., Haribabu, B., 2011. Deficiency of the leukotriene B4 receptor, BLT-1, protects against systemic insulin resistance in diet-induced obesity. J. Immunol. 187, 1942-1949. http://dx.doi.org/10.4049/jimmunol.1100196.

Spite, M., Claria, J., Serhan, C.N., 2014. Resolvins, specialized proresolving lipid mediators, and their potential roles in metabolic diseases. Cell Metab. 19, 21-36. http://dx.doi.org/10.1016/j.cmet.2013.10.006.

Steinberg, D., Vaughan, M., Nestel, P.J., Bergstrom, S., 1963. Effects of prostaglandin E opposing those of catecholamines on blood pressure and on triglyceride breakdown in adipose tissue. Biochem. Pharmacol. 12, 764-766.

Sugiura, T., Kondo, S., Sukagawa, A., Nakane, S., Shinoda, A., Itoh, K., Yamashita, A., Waku, K., 1995. 2-Arachidonoylglycerol: a possible endogenous cannabinoid receptor ligand in brain. Biochem. Biophys. Res. Commun. 215, 89-97.

Sugiura, M., Kono, K., Liu, H., Shimizugawa, T., Minekura, H., Spiegel, S., Kohama, T., 2002. Ceramide kinase, a novel lipid kinase. Molecular cloning and functional characterization. J. Biol. Chem. 277, 23294-23300. http://dx.doi.org/10.1074/ jbc.M201535200.

Summers, S.A., 2006. Ceramides in insulin resistance and lipotoxicity. Prog. Lipid Res. 45, 42-72. http://dx.doi.org/10.1016/j.plipres.2005.11.002.

Summers, S.A., Garza, L.A., Zhou, H., Birnbaum, M.J., 1998. Regulation of insulinstimulated glucose transporter GLUT4 translocation and Akt kinase activity by ceramide. Mol. Cell Biol. 18, 5457-5464.

Sztalryd, C., Xu, G., Dorward, H., Tansey, J.T., Contreras, J.A., Kimmel, A.R., Londos, C., 2003. Perilipin A is essential for the translocation of hormone-sensitive lipase during lipolytic activation. J. Cell Biol. 161, 1093-1103. http://dx.doi.org/ $10.1083 /$ jcb.200210169.

Tanigawa, K., Suzuki, K., Nakamura, K., Akama, T., Kawashima, A., Wu, H., Hayashi, M., Takahashi, S., Ikuyama, S., Ito, T., Ishii, N., 2008. Expression of adipose differentiation-related protein (ADRP) and perilipin in macrophages infected with Mycobacterium leprae. FEMS Microbiol. Lett. 289, 72-79. http:// dx.doi.org/10.1111/j.1574-6968.2008.01369.x.

Tansey, J.T., Sztalryd, C., Gruia-Gray, J., Roush, D.L., Zee, J.V., Gavrilova, O., Reitman, M.L., Deng, C.X., Li, C., Kimmel, A.R., Londos, C., 2001. Perilipin ablation results in a lean mouse with aberrant adipocyte lipolysis, enhanced leptin production, and resistance to diet-induced obesity. Proc. Natl. Acad. Sci. U. S. A. 98, 6494-6499. http://dx.doi.org/10.1073/pnas.101042998.

Thiam, A.R., Farese Jr., R.V., Walther, T.C., 2013. The biophysics and cell biology of lipid droplets. Nat. Rev. Mol. Cell Biol. 14, 775-786. http://dx.doi.org/10.1038/ nrm3699.

Tilg, H., Moschen, A.R., 2008. Insulin resistance, inflammation, and non-alcoholic fatty liver disease. Trends Endocrinol. Metab. 19, 371-379. http://dx.doi.org/ 10.1016/j.tem.2008.08.005.

Titos, E., Rius, B., Gonzalez-Periz, A., Lopez-Vicario, C., Moran-Salvador, E., MartinezClemente, M., Arroyo, V., Claria, J., 2011. Resolvin D1 and its precursor docosahexaenoic acid promote resolution of adipose tissue inflammation by eliciting macrophage polarization toward an M2-like phenotype. J. Immunol. 187, 5408-5418. http://dx.doi.org/10.4049/jimmunol.1100225.

Tsuboi, H., Sugimoto, Y., Kainoh, T., Ichikawa, A., 2004. Prostanoid EP4 receptor is involved in suppression of 3T3-L1 adipocyte differentiation. Biochem. Biophys. Res. Commun. 322, 1066-1072. http://dx.doi.org/10.1016/j.bbrc.2004.08.018.
Waltermann, M., Steinbuchel, A., 2005. Neutral lipid bodies in prokaryotes: recent insights into structure, formation, and relationship to eukaryotic lipid depots. J. Bacteriol. 187, 3607-3619. http://dx.doi.org/10.1128/JB.187.11.3607-3619.2005.

Wang, S.P., Laurin, N., Himms-Hagen, J., Rudnicki, M.A., Levy, E., Robert, M.F., Pan, L. Oligny, L., Mitchell, G.A., 2001. The adipose tissue phenotype of hormonesensitive lipase deficiency in mice. Obes. Res. 9, 119-128. http://dx.doi.org/ 10.1038/oby.2001.15.

Wang, H., Liu, H., Jia, Z., Olsen, C., Litwin, S., Guan, G., Yang, T., 2010. Nitro-oleic acid protects against endotoxin-induced endotoxemia and multiorgan injury in mice. Am. J. Physiol. Ren. Physiol. 298, F754-F762. http://dx.doi.org/10.1152/ ajprenal.00439.2009.

Wang, H., Liu, H., Jia, Z., Guan, G., Yang, T., 2010. Effects of endogenous PPAR agonist nitro-oleic acid on metabolic syndrome in obese zucker rats. PPAR Res. 2010, 601562. http://dx.doi.org/10.1155/2010/601562.

Wei, S., Lai, K., Patel, S., Piantedosi, R., Shen, H., Colantuoni, V., Kraemer, F.B. Blaner, W.S., 1997. Retinyl ester hydrolysis and retinol efflux from BFC-1beta adipocytes. J. Biol. Chem. 272, 14159-14165.

White, P.J., Arita, M., Taguchi, R., Kang, J.X., Marette, A., 2010. Transgenic restoration of long-chain n-3 fatty acids in insulin target tissues improves resolution capacity and alleviates obesity-linked inflammation and insulin resistance in high-fat-fed mice. Diabetes 59, 3066-3073. http://dx.doi.org/10.2337/db100054.

Wolins, N.E., Skinner, J.R., Schoenfish, M.J., Tzekov, A., Bensch, K.G., Bickel, P.E., 2003. Adipocyte protein S3-12 coats nascent lipid droplets. J. Biol. Chem. 278, 37713-37721. http://dx.doi.org/10.1074/jbc.M304025200.

Wolins, N.E., Quaynor, B.K., Skinner, J.R., Schoenfish, M.J., Tzekov, A., Bickel, P.E. 2005. S3-12, Adipophilin, and TIP47 package lipid in adipocytes. J. Biol. Chem. 280, 19146-19155. http://dx.doi.org/10.1074/jbc.M500978200.

Xie, W.L., Chipman, J.G., Robertson, D.L., Erikson, R.L., Simmons, D.L., 1991. Expression of a mitogen-responsive gene encoding prostaglandin synthase is regulated by mRNA splicing. Proc. Natl. Acad. Sci. U. S. A. 88, 2692-2696.

Xu, G., Sztalryd, C., Lu, X., Tansey, J.T., Gan, J., Dorward, H., Kimmel, A.R., Londos, C., 2005. Post-translational regulation of adipose differentiation-related protein by the ubiquitin/proteasome pathway. J. Biol. Chem. 280, 42841-42847. http:// dx.doi.org/10.1074/jbc.M506569200.

Xue, C., Liu, Y., Wang, J., Zhang, R., Zhang, Y., Zhang, J., Zhang, Y., Zheng, Z., Yu, X., Jing, H., Nosaka, N., Arai, C., Kasai, M., Aoyama, T., Wu, J., 2009. Consumption of medium- and long-chain triacylglycerols decreases body fat and blood triglyceride in Chinese hypertriglyceridemic subjects. Eur. J. Clin. Nutr. 63, 879-886. http://dx.doi.org/10.1038/ejcn.2008.76.

Yamamoto, K., Takeshita, M., Tokimitsu, I., Watanabe, H., Mizuno, T., Asakawa, H. Tokunaga, K., Tatsumi, T., Okazaki, M., Yagi, N., 2006. Diacylglycerol oil ingestion in type 2 diabetic patients with hypertriglyceridemia. Nutrition 22, 23-29. http://dx.doi.org/10.1016/j.nut.2005.04.009.

Yang, X., Lu, X., Lombes, M., Rha, G.B., Chi, Y.I., Guerin, T.M., Smart, E.J., Liu, J., 2010 The $G(0) / G(1)$ switch gene 2 regulates adipose lipolysis through association with adipose triglyceride lipase. Cell Metab. 11, 194-205. http://dx.doi.org/ 10.1016/j.cmet.2010.02.003.

Yore, M.M., Syed, I., Moraes-Vieira, P.M., Zhang, T., Herman, M.A., Homan, E.A. Patel, R.T., Lee, J., Chen, S., Peroni, O.D., Dhaneshwar, A.S., Hammarstedt, A. Smith, U., McGraw, T.E., Saghatelian, A., Kahn, B.B., 2014. Discovery of a class of endogenous mammalian lipids with anti-diabetic and anti-inflammatory effects. Cell 159, 318-332. http://dx.doi.org/10.1016/j.cell.2014.09.035.

You, T., Disanzo, B.L., Wang, X., Yang, R., Gong, D., 2011. Adipose tissue endocannabinoid system gene expression: depot differences and effects of diet and exercise. Lipids Health Dis. 10, 194. http://dx.doi.org/10.1186/1476-511X-10-194.

Zeldin, D.C., 2001. Epoxygenase pathways of arachidonic acid metabolism. J. Biol. Chem. 276, 36059-36062. http://dx.doi.org/10.1074/jbc.R100030200.

Zimmermann, R., Strauss, J.G., Haemmerle, G., Schoiswohl, G., BirnerGruenberger, R., Riederer, M., Lass, A., Neuberger, G., Eisenhaber, F., Hermetter, A., Zechner, R., 2004. Fat mobilization in adipose tissue is promoted by adipose triglyceride lipase. Science 306, 1383-1386. http://dx.doi.org 10.1126/science.1100747. 